\title{
SIN-dependent phosphoinhibition of formin multimerization controls fission yeast cytokinesis
}

\author{
K. Adam Bohnert, ${ }^{1}$ Agnieszka P. Grzegorzewska, ${ }^{2,3,6}$ Alaina H. Willet, ${ }^{1}$ Craig W. Vander Kooi, ${ }^{4,5}$ \\ David R. Kovar, ${ }^{2,3}$ and Kathleen L. Gould ${ }^{1,7}$ \\ ${ }^{1}$ Department of Cell and Developmental Biology, Vanderbilt University School of Medicine, Nashville, Tennessee 37232, USA; \\ ${ }^{2}$ Department of Molecular Genetics and Cell Biology, ${ }^{3}$ Department of Biochemistry and Molecular Biology, University of \\ Chicago, Chicago, Illinois 60637, USA; ${ }^{4}$ Department of Molecular and Cellular Biochemistry, ${ }^{5}$ Center for Structural Biology, \\ University of Kentucky, Lexington, Kentucky 40536, USA
}

Many eukaryotes accomplish cell division by building and constricting a medial actomyosin-based cytokinetic ring (CR). In Schizosaccharomyces pombe, a Hippo-related signaling pathway termed the septation initiation network (SIN) controls CR formation, maintenance, and constriction. However, how the SIN regulates integral CR components was unknown. Here, we identify the essential cytokinetic formin Cdc12 as a key CR substrate of SIN kinase Sid2. Eliminating Sid2-mediated Cdc12 phosphorylation leads to persistent Cdc12 clustering, which prevents CR assembly in the absence of anillin-like Mid1 and causes CRs to collapse when cytokinesis is delayed. Molecularly, Sid2 phosphorylation of Cdc12 abrogates multimerization of a previously unrecognized Cdc12 domain that confers F-actin bundling activity. Taken together, our findings identify a SIN-triggered oligomeric switch that modulates cytokinetic formin function, revealing a novel mechanism of actin cytoskeleton regulation during cell division.

[Keywords: cytokinesis; formin; phosphorylation; septation initiation network; oligomerization; F-actin bundling]

Supplemental material is available for this article.

Received June 10, 2013; revised version accepted August 28, 2013.

Cell division requires not only faithful duplication and segregation of the genome but also physical separation of daughter cells via cytokinesis. Because failure to complete cytokinesis can cause cell death or promote tumor formation (Fujiwara et al. 2005), relevant regulatory cues must fine-tune cytokinesis temporally and spatially. The fission yeast Schizosaccharomyces pombe, a leading model organism for cytokinesis studies, undergoes a well-defined order of events during cell division. At mitotic onset, early cytokinesis factors assemble into medial precursor nodes, from which a mature cytokinetic ring (CR) develops. Following nuclear division, the CR constricts as cell wall is deposited, forming a septum that will later be degraded to complete cell division (for review, see Pollard and Wu 2010).

Two distinct but synergistic pathways control $S$. pombe cytokinesis. The first originates at medial precursor nodes, where anillin-like Mid1 recruits multiple early CR proteins (Laporte et al. 2011). Search-capture-pull-release interactions between myosin and F-actin from distinct nodes then form a complete ring structure (Vavylonis

\footnotetext{
${ }^{6}$ Present address: Molecular Biology, Cell Biology, and Biochemistry Program, Boston University, Boston, MA 02215, USA.

${ }^{7}$ Corresponding author

E-mail kathy.gould@vanderbilt.edu

Article is online at http://www.genesdev.org/cgi/doi/10.1101/gad.224154.113.
}

et al. 2008). Despite this early cytokinesis function, Mid1 is nonessential, and cells lacking Mid1 undergo cytokinesis, albeit more slowly and at inappropriate angles and locations (Chang et al. 1996; Sohrmann et al. 1996; Huang et al. 2008; Saha and Pollard 2012). The septation initiation network (SIN), a GTPase-regulated kinase cascade related to the Hippo pathway (Hergovich and Hemmings 2012), constitutes a second cytokinesis pathway, which operates independently of nodes and Midl (Hachet and Simanis 2008; Huang et al. 2008). SIN proteins assemble at spindle pole bodies (SPBs), although the terminal SIN kinase Sid2, like its human homolog (Bothos et al. 2005), translocates to the CR during cytokinesis (Johnson et al. 2012). Consistent with the SIN being sufficient for CR assembly in $S$. pombe, precocious SIN activation drives multiple rounds of septation in interphase and permits orthogonal CR formation in mid1s cells (Minet et al. 1979; Huang et al. 2008). The SIN also governs CR maintenance following node-initiated cytokinesis, and CRs collapse between segregated daughter nuclei when SIN signaling is selec-

(C) 2013 Bohnert et al. This article is distributed exclusively by Cold Spring Harbor Laboratory Press for the first six months after the full-issue publication date (see http://genesdev.cshlp.org/site/misc/terms.xhtml). After six months, it is available under a Creative Commons License (Attribution-NonCommercial 3.0 Unported), as described at http:// creativecommons.org/licenses/by-nc/3.0/. 
tively abolished (Le Goff et al. 1999; Liu et al. 1999; Mishra et al. 2004; Hachet and Simanis 2008).

Given that SIN signaling culminates with kinase Sid2 targeting to the CR (Johnson et al. 2012), protein phosphorylation likely directs the major functional SIN output during cytokinesis. Indeed, Sid2 phosphorylates the nonessential Cdc14 phosphatase Clp1 to foster Clp1's cytoplasmic retention (Chen et al. 2008). Cytoplasmic Clp1 in turn dephosphorylates the essential F-BAR scaffold protein Cdc15 (Clifford et al. 2008), helping to induce a conformational change in Cdc15 that promotes CR assembly (Roberts-Galbraith et al. 2010). Although Cdc15 accumulation within a ring structure ultimately requires SIN activation (Hachet and Simanis 2008), there is no evidence that Cdc15 is a direct SIN target. While other SIN substrates besides Clp1 have been identified (Feoktistova et al. 2012; Grallert et al. 2012; Mana-Capelli et al. 2012; Gupta et al. 2013), none account for the essential role of the SIN in Mid1-independent CR assembly.

Cytokinesis in fission yeast, as in most eukaryotes, is actomyosin-based (Guertin et al. 2002). Accordingly, formin Cdc12, which localizes to the CR (Chang et al. 1997) and nucleates and processively elongates F-actin through its formin homology 1 (FH1) and FH2 domains (Kovar et al. 2003; Kovar and Pollard 2004), is an essential component of the $S$. pombe cytokinetic machinery (Chang et al. 1997). As Cdc12 hyperactivity is lethal (Chang et al. 1997; Kovar et al. 2003), it seems likely that Cdc12 function is tightly regulated. Nonetheless, regulatory mechanisms have not been identified. Domains homologous to autoinhibitory DID and DAD motifs appear inactive (Yonetani et al. 2008), and posttranslational control of Cdc12 has not been reported.

\section{Results}

The SIN kinase Sid2 phosphorylates cytokinetic formin Cdc12

To assess potential cell cycle regulation of formin Cdc12, we analyzed the SDS-PAGE mobility of $\mathrm{Cdc} 12-\mathrm{HA}_{3}$ through the cell cycle. Intriguingly, Cdc12- $\mathrm{HA}_{3}$ migrated more slowly during nuclear division just prior to septation (Fig. 1A). $\lambda$-Phosphatase treatment of Cdc12-HA 3 immunoprecipitates from selected samples indicated that gel mobility shifts were due to phosphorylation and that Cdc12$\mathrm{HA}_{3}$ was hyperphosphorylated immediately before septation (Fig. 1B). Similar gel mobility patterns were observed for Cdc12 tagged with a different epitope $\left(\mathrm{V}_{3}\right)$ and released from an S-phase arrest (Supplemental Fig. 1A). $\lambda$-Phosphatase treatment of $\mathrm{Cdc} 12-\mathrm{V}_{3}$ immunoprecipitates from cytokinesis-arrested cells (which block after CR formation due to impaired septum deposition) (Le Goff et al. 1999; Liu et al. 2000) or G1-arrested cells confirmed that Cdc12 phosphorylation peaks during cell division (Fig. 1C).

Given this phosphorylation pattern, we asked whether the SIN, whose activity increases during mitosis and is maintained during a cytokinesis arrest (Liu et al. 1999; Sparks et al. 1999), directly targets Cdc12. We found that SIN induction achieved via inactivation of the inhibitory GAP Cdc16 (Minet et al. 1979) resulted in Cdc12-V5 hyperphosphorylation (Fig. 1D). Moreover, the SIN kinase Sid2, which localizes to SPBs and the CR during a cps1-191 cytokinesis arrest (Supplemental Fig. 1B,C), directly phosphorylated MBP-tagged Cdc12 fragments in vitro (Fig. 1E; Supplemental Fig. 1D,E), and Cdc12-Flag 3 from cps1-191 sid2-250 arrested cells exhibited faster gel mobility compared with Cdc12-Flag 3 from cps1-191 arrested cells (Fig. 1F). In accord with Sid2 family kinases targeting RxxS motifs (Mah et al. 2005), Sid2 phosphorylated exclusively serines on Cdc12 fragments (Supplemental Fig. 1F). Alanine mutation of Sid2 consensus serines identified residues S824, S1523, S1543, and S1811 as the major Sid2 targeted residues (Fig. 1E; Supplemental Fig. 1G). All four of these sites reside outside of well-characterized formin domains (Fig. 1G). Cells were viable when wild-type $c d c 12^{+}$was replaced with $c d c 12-4 A$, in which the four Sid2 targeted serines are mutated to alanines. However, Cdc12-4A-Flag 3 was not hyperphosphorylated to the same extent as wild-type Cdc12-Flag 3 during a cps1-191 cytokinesis arrest (Fig. 1F), signifying that Cdc12-4A cannot be fully phosphorylated in vivo. Therefore, we concluded that Sid2 phosphorylates formin Cdc12 during cytokinesis.

\section{Cdc12-4A clusters abnormally and compromises actomyosin function during cell division}

During cytokinesis, wild-type Cdc12-GFP 3 localizes only to the CR (Fig. 2A,B), although Cdc12-GFP 3 can assemble spots during interphase (Fig. 2B). In contrast, Cdc12$4 \mathrm{~A}-\mathrm{GFP}_{3}$ formed spots that were not restricted to interphase but persisted throughout cell division in $51 \%$ (32 of 63) of cells (Fig. 2C). While Cdc12-4A-GFP 3 also localized to CRs (Fig. 2C), which formed from nodes but with a slight delay in the $c d c 12-4 A$ genetic background (Supplemental Fig. 2A,B), CR-localized Cdc12-4A-GFP 3 appeared more punctate and discontinuous than normal (Fig. 2C). During CR constriction, Cdc12-4A-GFP 3 clustered into additional nonmedial spots (Fig. 2C), which colocalized with SPBs (Fig. 2D) and required SPB/SIN scaffold Sid4 for their nuclear apposition (Supplemental Fig. 2C). Intriguingly, wild-type Cdc12-GFP 3 was also detected at SPBs during cytokinesis upon transient inactivation of an analog-sensitive Sid2 mutant (Fig. 2E), validating that Cdc12 SPB localization arises from loss of a Sid2 input.

Consistent with Cdc12-4A being deregulated, combining the $c d c 12-4 A$ allele with various loss-of-function alleles in the cytokinetic actomyosin machinery revealed severe negative genetic interactions (Supplemental Fig. $2 \mathrm{D}, \mathrm{E})$. cdc12-4A cells treated with low-dose $(0.2 \mu \mathrm{M})$ latrunculin $\mathrm{A}$ (Lat $\mathrm{A}$ ), which impedes actin polymerization (Ayscough et al. 1997), also exhibited grossly amplified cytokinetic errors (Supplemental Fig. 2F,G), similar to Lat A-treated cells lacking the SIN target Clp1 (Mishra et al. 2004). Thus, loss of Sid2-mediated Cdc12 phosphorylation alters formin targeting and compromises the robust performance of the cytokinetic actomyosin machinery.

\section{Cdc12-4A is defective in SIN-dependent cytokinesis}

We next tested whether SIN-dependent events during cytokinesis were impaired in the $c d c 12-4 A$ mutant. Upstream 
Bohnert et al.

A

\begin{tabular}{rcccccccccc} 
& \multicolumn{1}{c}{$c d c 25-22$} & $c d c 12-\mathrm{HA}_{3}$ G2 block and release \\
\cline { 2 - 11 } Time: & 0 & 15 & 30 & 45 & 60 & 75 & 90 & 105 & 120 & 135 \\
Binucleate \%: & 0 & 1 & 17 & 47 & 70 & 26 & 5 & 2 & 0 & 2 \\
Septation \%: & 1 & 0 & 1 & 4 & 24 & 57 & 83 & 38 & 18 & 5
\end{tabular}

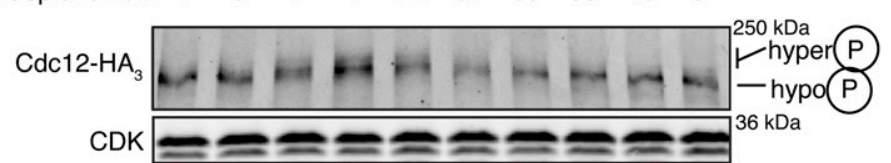

B

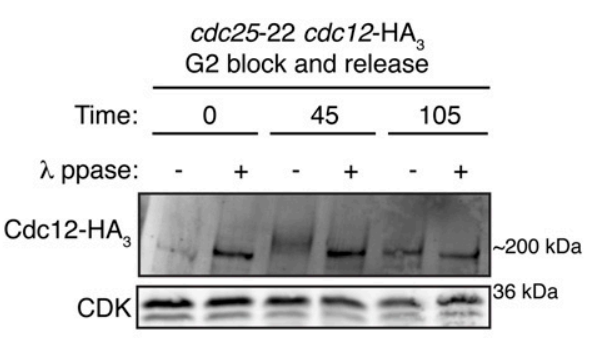

D

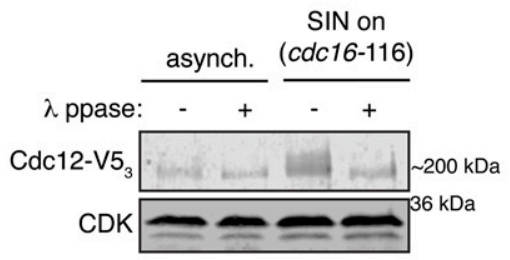

E

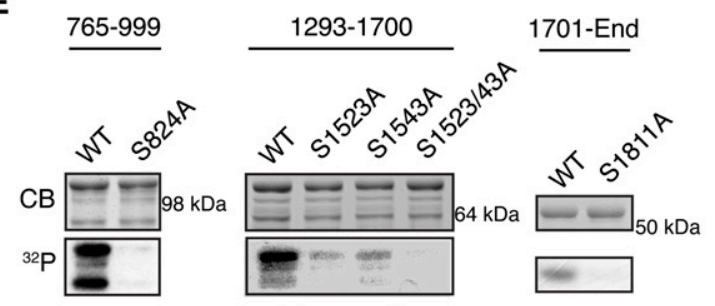

G

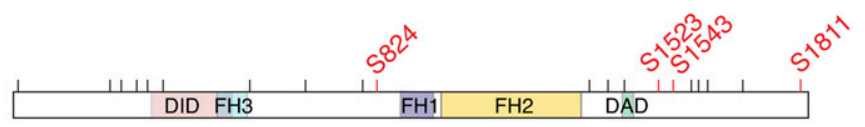

C

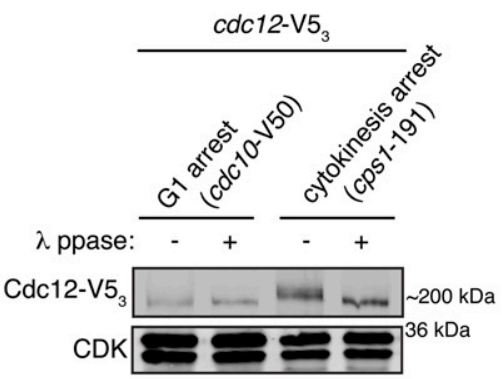

$\mathbf{F}$

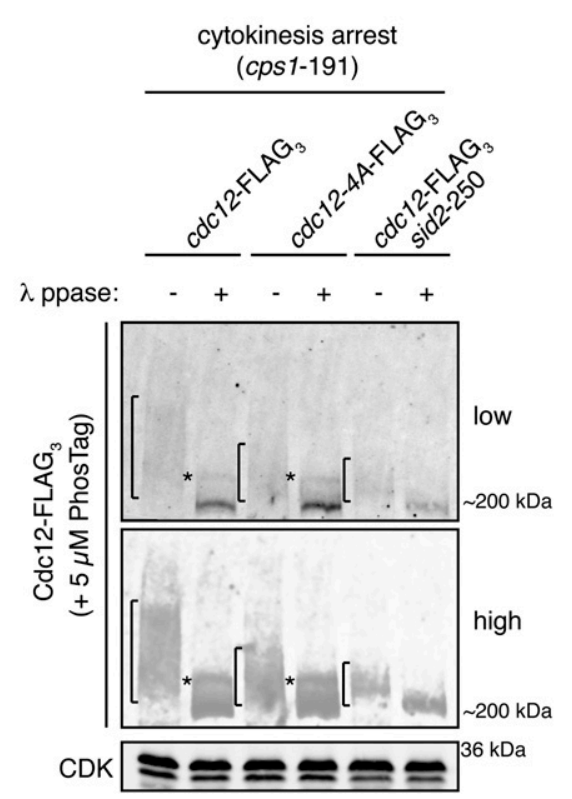

Figure 1. The SIN kinase Sid2 participates in Cdc12 hyperphosphorylation during cytokinesis. $(A)$ Block and release of $c d c 25-22$ cdc12- $-\mathrm{HA}_{3}$ cells. At the indicated time points, cell cycle progression was monitored by binucleate and septation percentages. Denatured cell lysates were prepared from the different time points. Anti-HA immunoprecipitates of the samples were resolved by SDS-PAGE and immunoblotted. CDK was used as a loading control. (B) Denatured cell lysates were prepared from duplicate samples of the indicated time points in $A$. Anti-HA immunoprecipitates of samples were subjected to either phosphatase treatment or a buffer control before being resolved by SDS-PAGE and immunoblotted. CDK was used as a loading control. $(C)$ Denatured cell lysates were prepared from $c d c 10-\mathrm{V} 50 c d c 12-\mathrm{V} 5_{3}$ or $c p s 1-191 c d c 12-\mathrm{V} 5_{3}$ cells arrested at the indicated stages. Anti-V5 immunoprecipitates of the samples were subjected to either phosphatase treatment or a buffer control before being resolved by SDS-PAGE and immunoblotted. CDK was used as a loading control. $(D)$ Denatured cell lysates were prepared from asynchronous $c d c 12-\mathrm{V} 55_{3}$ or SIN-activated $c d c 16-116$ $c d c 12-\mathrm{V} 5_{3}$ cells. Anti-V5 immunoprecipitates of the samples were subjected to either phosphatase treatment or a buffer control before being resolved by SDS-PAGE and immunoblotted. CDK was used as a loading control. (E) In vitro kinase assays using Sid2-Myc ${ }_{13}$ immunoprecipitated from $c d c 16-116$ sid2- $\mathrm{Myc}_{13}$ cells and various recombinant MBP-Cdc12 wild-type and mutant fragments. The protein gel was stained with Coomassie blue $(\mathrm{CB})$, and proteins labeled by $\gamma-\mathrm{P}^{32}$ were detected by autoradiography. Only mutants with a loss in phosphorylation are shown. $(F)$ Denatured cell lysates were prepared from cytokinesis-arrested $c p s 1-191$ cdc12-Flag $_{3}$, $c p s 1-191$ $c d c 12-4 A-F_{a g}$, or $c p s 1-191$ sid2-250 cdc12-Flag ${ }_{3}$ cells. Anti-Flag immunoprecipitates of the samples were subjected to either phosphatase treatment or a buffer control before being resolved by SDS-PAGE and immunoblotted. PhosTag (5 $\mu \mathrm{m})$ was included in the protein gel to enhance separation. Brackets span phosphorylated smears, and asterisks denote a noncollapsible species. CDK was used as a loading control. $(G)$ Schematic of Cdc12, with Sid2 targeted residues labeled in red, and nonphosphorylated Sid2 consensus motifs marked by black ticks. 
A

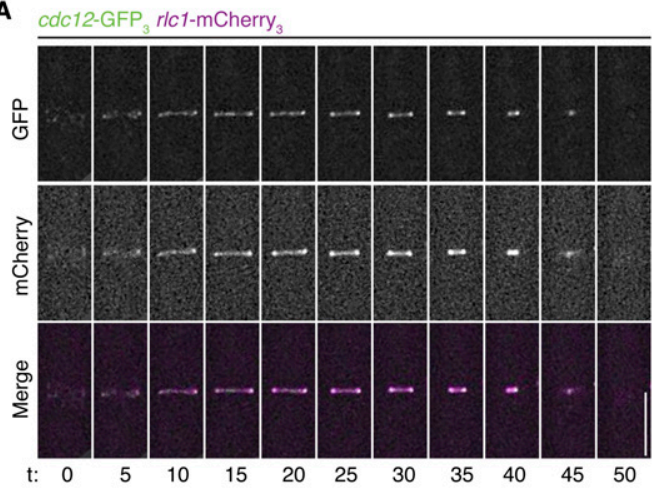

C

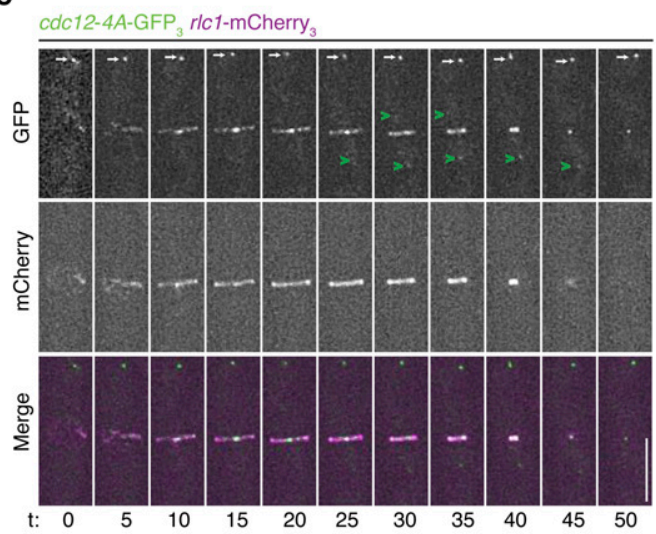

E

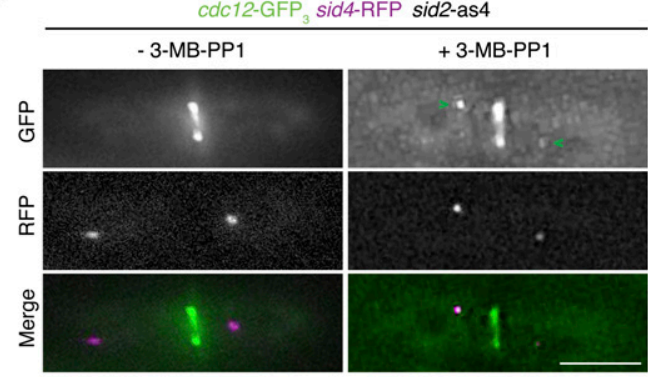

B

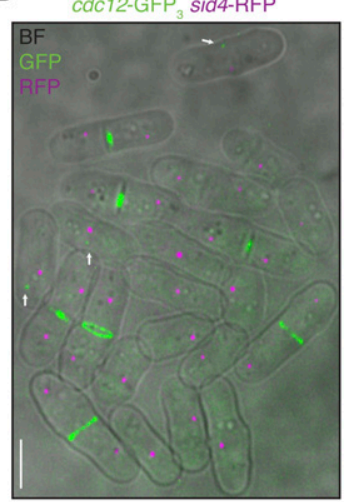

D

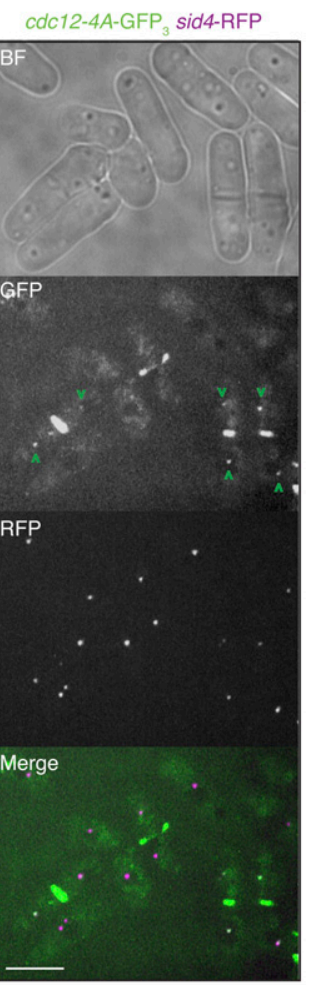

Figure 2. Loss of SIN-mediated formin phosphorylation results in abnormal Cdc12 clustering at mitotic spots and SPBs. (A) Live-cell GFP/mCherry movie of a $c d c 12-\mathrm{GFP}_{3}$ rlc1-mCherry ${ }_{3}$ cell during cell division. Images were acquired every $5 \mathrm{~min} .(B)$ Live-cell bright-field/GFP/RFP merged image of asynchronous $c d c 12-\mathrm{GFP}_{3}$ sid4-RFP cells. Arrows indicate Cdc12 interphase spots. $(C)$ Live-cell GFP/ mCherry movie of a $c d c 12-4 A-\mathrm{GFP}_{3}$ rlc1-mCherry 3 cell during cell division. Images were acquired every $5 \mathrm{~min}$. White arrows mark an interphase spot that persists throughout cell division, and green arrowheads indicate SPB localization. $(D)$ Live-cell bright-field, GFP, RFP, and GFP/RFP merged images of asynchronous $c d c 12-4 A-\mathrm{GFP}_{3}$ sid4-RFP cells. Green arrowheads indicate SPB localization. (E) Live-cell GFP, RFP, and GFP/RFP merged images of $c d c 12-\mathrm{GFP}_{3}$ sid4-RFP sid2-as4 cells treated with $20 \mu \mathrm{M} 3-\mathrm{MB}-\mathrm{PP} 1$ or untreated. Green arrowheads indicate SPB localization. Bars, $5 \mu \mathrm{m}$.
SIN activation appeared unperturbed in $c d c 12-4 A$ cells, as evidenced by asymmetry of SIN kinase Cdc7, CR localization of Sid2, and Sid2 kinase activity (Supplemental Fig. 3A-C; Johnson et al. 2012). Thus, we reasoned that any SIN defects observed in the $c d c 12-4 A$ mutant were due to eliminating Cdc12 phosphorylation by Sid2. Because the SIN is critical for Mid1/node-independent cytokinesis (Hachet and Simanis 2008; Huang et al. 2008), we combined mid1s and $c d c 12-4 A$ alleles. Importantly, $c d c 12-4 A$ mid1s cells were significantly more defective in cytokinesis than either individual mutant (Fig. 3A; Supplemental Fig. 3D) and died at elevated temperatures (Supplemental Fig. 3E). F-BAR protein Cdc15 is also vital for Mid1independent cytokinesis (Hachet and Simanis 2008), and Sid2-mediated phosphorylation of Cdc14 family phosphatase Clp1 facilitates Cdc15 dephosphorylation and activation (Chen et al. 2008; Clifford et al. 2008; Roberts-Galbraith et al. 2010). Accordingly, cdc12-4A was synthetically sick with a $c d c 15$ temperature-sensitive allele (Supplemental Fig. 3F) and exaggerated cytokinesis defects of a $c l p 1-6 A$ GFP allele (Supplemental Fig. 3G,H), which eliminates SIN-dependent Clp1 phosphorylation (Chen et al. 2008). These results are consistent with Sid2-mediated Cdc12 phosphorylation representing an important facet of downstream SIN-based CR regulation.

To further explore the contribution of Cdc12 phosphorylation to SIN signaling, we tested whether cdc12-4A cells were capable of interphase CR assembly and septation upon SIN hyperactivation. We used a temperaturesensitive allele of the inhibitory GAP Cdc16, which, when inactivated, leads to multiple rounds of CR formation and septation (Fig. 3B; Minet et al. 1979). Cells were synchronized in G2 phase (Fig. 3C; Supplemental Fig. 3I) by centrifugal elutriation and then shifted to the restrictive 
Bohnert et al.

A

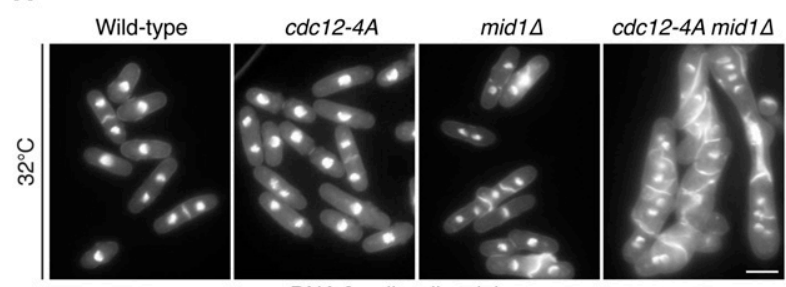

DNA \& cell wall staining

C

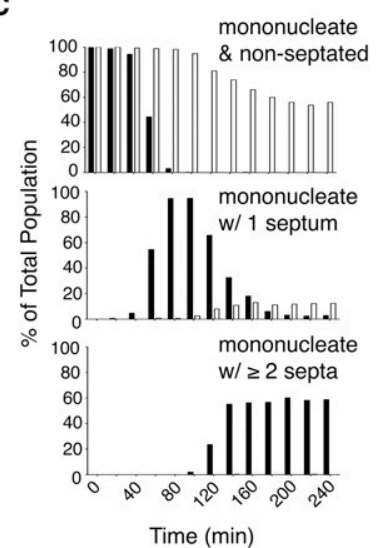

- cdc16-116 cdc12-V5 ㅁ cdc16-116 cdc12-4A-V5

D

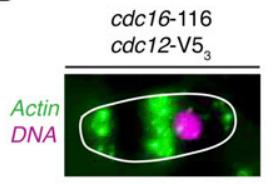

E
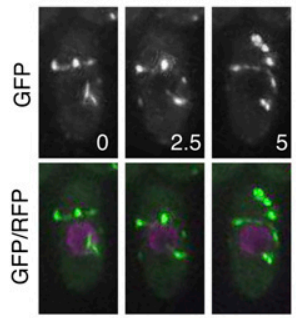
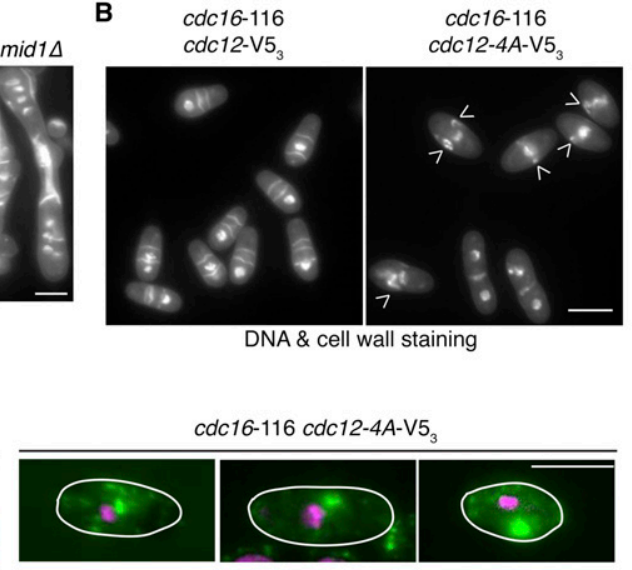

DNA \& cell wall staining

列

(shifted into restrictive temperature)
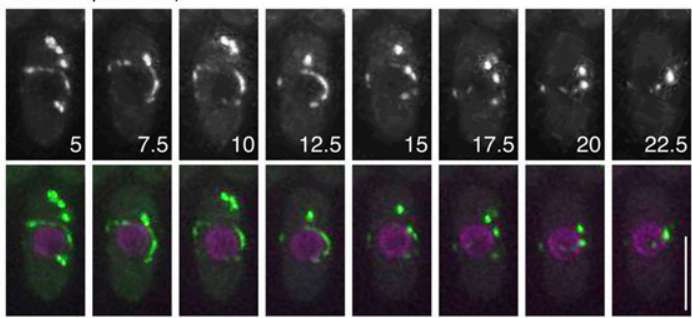

F

cdc16-116 cdc12-V5 ${ }_{3}$ cdc15-GFP rpn11-RFP

(shifted into restrictive temperature)
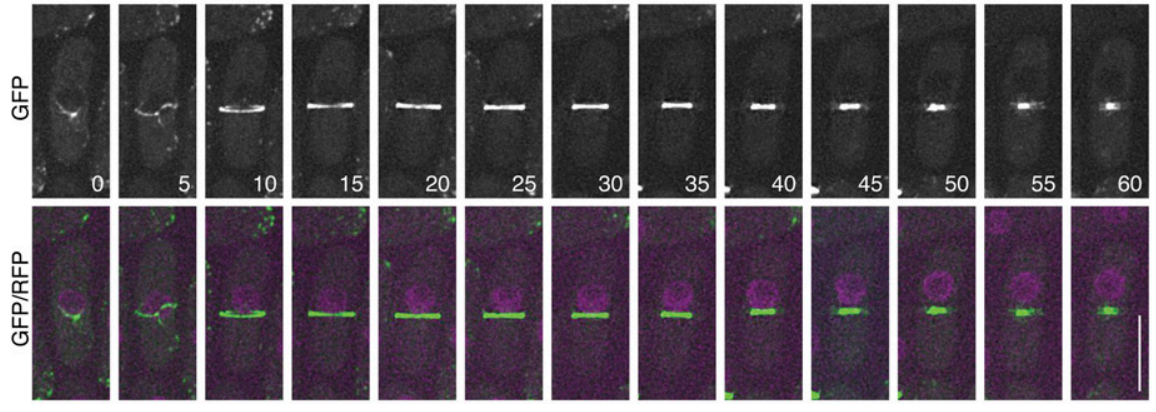

Figure 3. Mid1/node-independent cytokinesis requires Sid2-mediated Cdc12 phosphorylation. $(A)$ Fixed-cell images of DAPI-stained and methyl blue-stained wild-type, $c d c 12-4 A$, mid1 $1 \Delta$, and $c d c 12-4 A$ mid1 $\Delta$ cells grown at $32^{\circ} \mathrm{C}$. (B) Fixed-cell images of DAPI-stained and methyl blue-stained $c d c 16-116 c d c 12-\mathrm{V}_{3}$ and $c d c 16-116 c d c 12-4 A-\mathrm{V} 5_{3}$ cells after $4 \mathrm{~h}$ at the restrictive temperature. Arrowheads indicate abnormal cell wall deposits in mononucleate cells. $(C)$ Quantification of septation upon SIN induction in $c d c 16-116 c d c 12-V 5_{3}$ and $c d c 16-116 c d c 12-4 A-V 5_{3}$ mononucleate cells. Cells were initially synchronized by centrifugal elutriation and then shifted for $4 \mathrm{~h}$ to the restrictive temperature. $n>300$ for each time point. $(D)$ Fixed-cell images of phalloidin-stained (green) and DAPI-stained (magenta) $c d c 16-116 c d c 12-\mathrm{V} 5_{3}$ and $c d c 16-116 c d c 12-4 A-\mathrm{V} 5_{3}$ cells after $4 \mathrm{~h}$ at the restrictive temperature. $(E)$ Live-cell GFP/RFP movie of a $c d c 16-$ $116 c d c 12-4 A-\mathrm{V}_{3} c d c 15-\mathrm{GFP}$ rpn11-RFP interphase cell just after being shifted to the restrictive temperature. Rpn11-mCherry marks the nucleus (Kouranti et al. 2010). Images were acquired every $2.5 \mathrm{~min}$. (F) Live-cell GFP/RFP movie of a $c d c 16-116 c d c 12-\mathrm{V} 5_{3} c d c 15$ GFP rpn11-RFP interphase cell just after being shifted to the restrictive temperature. Images were acquired every 2.5 min, and representative images are shown. Bars, $5 \mu \mathrm{m}$.

temperature. Mononucleate $c d c 12-\mathrm{V} 5_{3}$ cells septated almost immediately, and nearly all mononucleates developed multiple septa within $4 \mathrm{~h}$ (Fig. 3B,C). However, a majority of $c d c 12-4 A-\mathrm{V} 55_{3}$ mononucleates failed to septate within this time frame (Fig. 3B,C). Instead, these cells accumulated abnormal cell wall deposits near their cell middles (Fig. 3B). cdc12- $4 \mathrm{~A}-\mathrm{V} 5_{3}$ mutants also contained medial spots, but not rings, of actin and CR proteins IQGAP YFP-Rng2 and Cdc15-GFP (Fig. 3D; Supplemental Fig. 3J), which arose from earlier filament-like structures that fragmented and subsequently clustered into distinct foci (Fig. 3E). CR fragmentation was not observed upon interphase SIN induction in a $c d c 12^{+}$genetic background (Fig. 3F). Like cdc16-116 cdc12-V5 ${ }_{3}$ cells, cdc16-116 cdc12-4A-V5 ${ }_{3}$ cells 
that slipped into mitosis completed medial septation (Fig. 3B; Supplemental Fig. 3K), illustrating that the $c d c 12-4 \mathrm{~A}$ allele does not block node-based cytokinesis. However, additional nonmedial septa never formed in cdc16-116 $c d c 12-4 A$-V $5_{3}$ binucleates (Fig. 3B; Supplemental Fig. 3K), consistent with the $c d c 12-4 A$ allele eliminating a key SIN signal.

\section{Prolonged CR maintenance requires Sid2-mediated Cdc12 phosphorylation}

Even when Mid1/node-based modules contribute to CR assembly at mitotic onset, sustained CR integrity demands SIN signaling. This is most evident in a cps1-191 $\beta$-glucan synthase mutant, which conditionally activates a cytokinetic checkpoint due to impaired septum deposition (Le Goff et al. 1999; Liu et al. 2000). Although cps1-191 cells form CRs, these mutants require SIN activity for CR maintenance during the arrest (Liu et al. 1999; Mishra et al. 2004; Hachet and Simanis 2008). Consistent with Sid2-mediated Cdc12 phosphorylation constituting a critical SIN signal, intact F-actin rings were not observed in cps1-191 cdc12-4A arrested cells as they were in cps1-191 arrested cells (Fig. 4A). Similar to cps1-191 sid2250 double mutants (Hachet and Simanis 2008), cps1-191 cdc12-4A cells often contained medial F-actin clumps flanking "kissing nuclei" that had returned to cell middles following failed cytokinesis (Fig. 4A). We found that these F-actin defects were associated with Cdc12 mislocalization. Whereas $\mathrm{Cdc}_{12}-\mathrm{GFP}_{3}$ maintained a ring structure during a cps1-191 arrest (Fig. 4B), it accumulated in medial spots in cps1-191 sid2-250 arrested cells (Fig. 4B). Cdc12-4A-GFP ${ }_{3}$ formed similar spot-like structures in a cps1-191 arrest (Fig. 4B), validating that Sid2 cannot target Cdc12-4A.

We predicted that the spot-like structures observed in the cdc12-4A mutant originated from CRs collapsing during the cytokinesis arrest. While wild-type Cdc12$\mathrm{GFP}_{3}$ and $\mathrm{CR}$ marker Rlc1-mCherry ${ }_{3}$ persisted in a ring at the division site in a cps1-191 arrest (Fig. 4C), cdc12-4A cells formed CRs that indeed later collapsed and clustered into a medial mass during the arrest (Fig. 4D). Thus, Sid2-mediated Cdc12 phosphorylation is required for SINdependent CR maintenance.

\section{Sid2-mediated phosphorylation inhibits Cdc12 C-terminal multimerization}

Sid2 phosphorylates Cdc12 on residues located outside of characterized formin domains (Fig. 5A). Thus, we assessed whether Sid2-mediated phosphorylation disrupts the function of an uncharacterized Cdc12 domain. To identify such a domain, we introduced C-terminal tags at the endogenous $c d c 12^{+}$locus to produce serial 100-residue truncations (Supplemental Fig. 4A). Although overexpression of similar C-terminal truncations is lethal (Yonetani and Chang 2010), we found that endogenous $c d c 12$ truncations lacking residues C-terminal to Cdc12's FH2 domain were viable (Supplemental Fig. 4B). Despite comparable viability, these mutants differed in CR phenotypes. Whereas Cdc12(1-1600)-GFP 3 formed complete ring structures,
Cdc12(1-1400)-GFP 3 was discontinuous (Fig. 5B). Thus, we predicted that residues 1400-1600 contain a domain critical to Cdc12 regulation. In complementary experiments, we found that overexpressing the $\mathrm{Cdc} 12 \mathrm{C}$ terminus strongly inhibited cytokinesis (Supplemental Fig. 4C,D). We also defined a minimal C-terminal fragment (residues 14511538) that was sufficient for this activity (Fig. 5C; Supplemental Fig. $4 \mathrm{C}, \mathrm{D})$. Importantly, this fragment overlaps with the region contributing to $\mathrm{CR}$ formation (Fig. 5A,B), suggesting that residues 1451-1538 comprise a functional domain.

Sequence analysis revealed a high percentage of basic and serine residues within this region (Supplemental Fig. $5 \mathrm{~A})$, reminiscent of RS domains involved in oligomerization (Boucher et al. 2001). Accordingly, when resolved under native conditions, His $_{6}$-Cdc12(1451-1538) was detected in various multimeric forms (Fig. 5D), suggesting that it oligomerized. Consistent with self-association, MBPCdc12(1451-1538) and His $_{6}$-Cdc12(1451-1538) interacted in vitro (Fig. 5E). Although cdc12(1451-1538) overexpression in cells did not immediately affect SIN activation (Supplemental Fig. 5B), such overexpression drove endogenous Cdc12- $\mathrm{GFP}_{3}$ into spot-like structures (Fig. 5F), which formed from collapsed CRs in nonseptated cells (Supplemental Fig. 5C). Furthermore, overexpressed GFPcdc12(1451-1538) itself was detectable in clusters at separated SPBs when the cellular signal intensity was not overamplified (Supplemental Fig. 5B,D). In line with $c d c 12(1451-1538)$ functioning as a dominant-negative to wild-type $c d c 12^{+}$, overexpression of this domain was less toxic in a $c d c 12 \Delta 1451-1538$ mutant lacking these residues endogenously (Supplemental Fig. 5E). We also found that endogenous Cdc12 $\Delta 1451-1538-\mathrm{GFP}_{3}$, unlike wild-type Cdc12-GFP 3 (Coffman et al. 2009), never formed interphase spots (Supplemental Fig. 5F,G). Thus, residues 1451-1538 function as an oligomerization domain, which influences Cdc12 clustering.

RS domain-mediated oligomerizations can be reversed via phosphorylation (Nikolakaki et al. 2008; Peng et al. 2008). As two Sid2-directed phosphosites were within or near the Cdc12 oligomerization domain (Fig. 5A) and Cdc12 clustered during cytokinesis upon loss of this phosphorylation (Fig. 4B), we asked whether Sid2-mediated Cdc12 phosphorylation regulates this self-interaction. First, we immunoprecipitated wild-type Cdc12-Flag 3 or phosphomutant Cdc12-4A-Flag 3 from a cps1-191 arrest in which wild-type Cdc12 is phosphorylated by Sid2 (Fig. 1F) and tested whether immunoprecipitates bound $\mathrm{His}_{6^{-}}$ Cdc12(1451-1538). Only Cdc12-4A-Flag 3 bound His $_{6}-$ Cdc12(1451-1538) (Fig. 5G). Next, we repeated the in vitro binding experiments with recombinant proteins, but bead-bound MBP-Cdc12(1451-1538) was phosphorylated by Sid2-Myc 13 prior to incubation. We found that phosphorylation by Sid2-Myc ${ }_{13}$ significantly abrogated the self-interaction (Fig. 5H). Consistent with phosphorylation negatively regulating oligomerization, alanine mutation of S1523 in cdc12(1451-1538) created a stronger dominant-negative that hastened cytokinesis defects upon overexpression (Supplemental Fig. 5H,II. Collectively, these data indicate that Sid2-mediated Cdc12 phosphorylation counteracts $\mathrm{C}$-terminal self-interaction and that 
Bohnert et al.
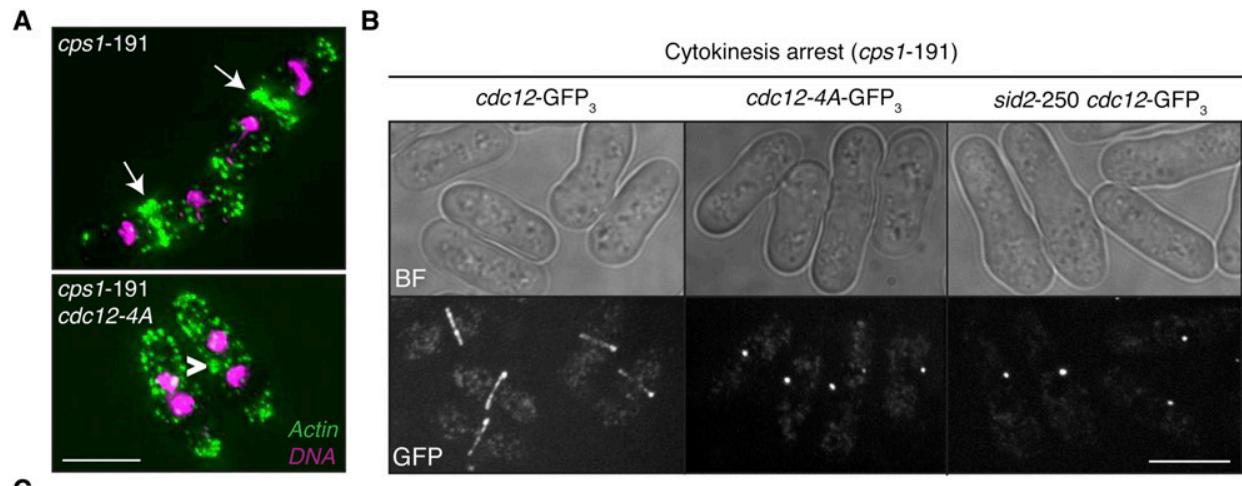

C

cps1-191 cdc12-GFP ${ }_{3}$ rlc1-mCherry ${ }_{3}$ shifted into a cytokinesis arrest

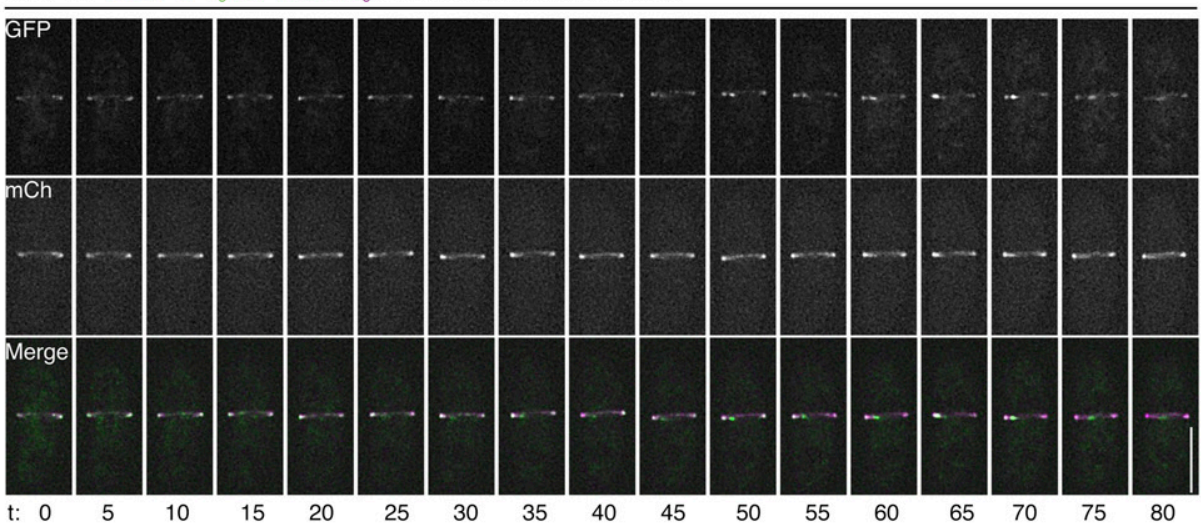

D

cps1-191 cdc12-4A-GFP ${ }_{3}$ rlc1-mCherry ${ }_{3}$ shifted into a cytokinesis arrest

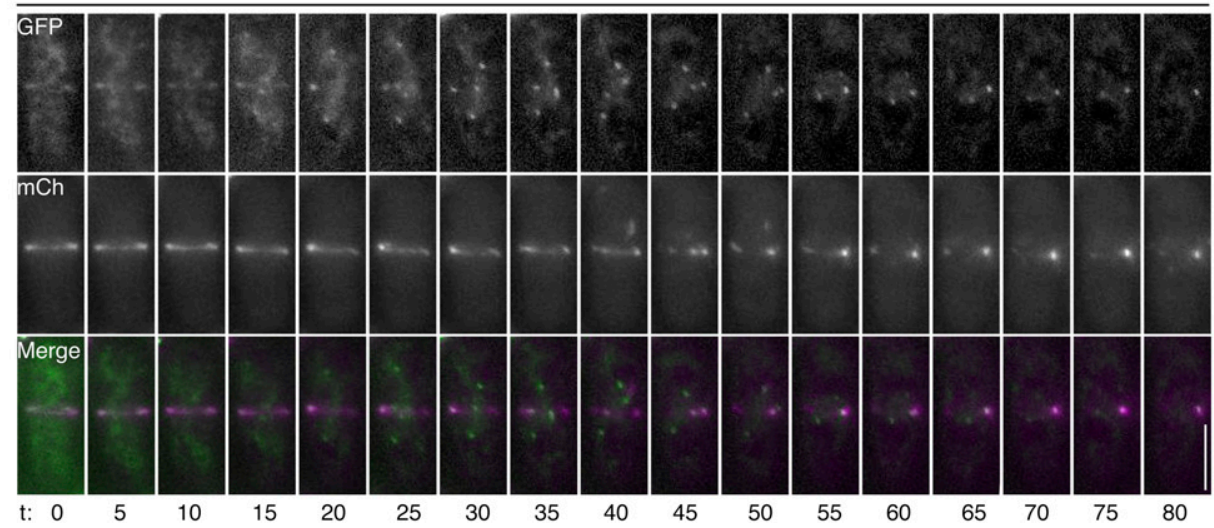

Figure 4. Phosphomutant Cdc12 does not maintain a CR but collapses into a spot during a cytokinesis arrest. $(A)$ Fixed-cell images of phalloidin-stained (green) and DAPI-stained (magenta) cps1-191 and cps1-191 cdc12-4A cells shifted for $3 \mathrm{~h}$ to $36^{\circ} \mathrm{C}$. Arrows indicate actin CRs, whereas an arrowhead points to a medial actin mass. (B) Live-cell bright-field and GFP images of $c p s 1-191$ cdc12-GFP 3 , $c p s 1$ 191 cdc12-4A-GFP ${ }_{3}$, and cps1-191 sid2-250 cdc12-GFP ${ }_{3}$ cells shifted for $3 \mathrm{~h}$ to $36^{\circ} \mathrm{C}$. (C) Live-cell GFP/mCherry movie of a $c p s 1-191$ $c d c 12-\mathrm{GFP}_{3}$ rlc1-mCherry ${ }_{3}$ cell just after being shifted to the restrictive temperature. Images were acquired every 5 min. $(D)$ Live-cell $\mathrm{GFP} / \mathrm{mCherry}$ movie of a cps1-191 cdc12-4A-GFP rlc1-mCherry $_{3}$ cell just after being shifted to the restrictive temperature. Images were acquired every $5 \mathrm{~min}$. Bars, $5 \mu \mathrm{m}$.

abnormal Cdc12 clustering occurs when multimerization persists.

The Cdc12 C-terminal oligomerization domain facilitates linear F-actin bundling

Deletion of the Cdc12 C terminus could preclude clustering even when CRs deteriorated during a cps1-191 arrest (Supplemental Fig. 6A). However, loss of the Cdc12 C terminus compromised CR formation (Fig. 5B), hinting that oligomerization may be important earlier during cytokinesis. Because the endogenous cdc12414511538 allele, but not $c d c 12-4 A$, was synthetically sick with fim $1 \Delta$ (Fig. 6A,B), a deletion of a reported F-actin bundler at the S. pombe CR (Skau et al. 2011), we investigated the possibility that Cdc12 multimerization 
A

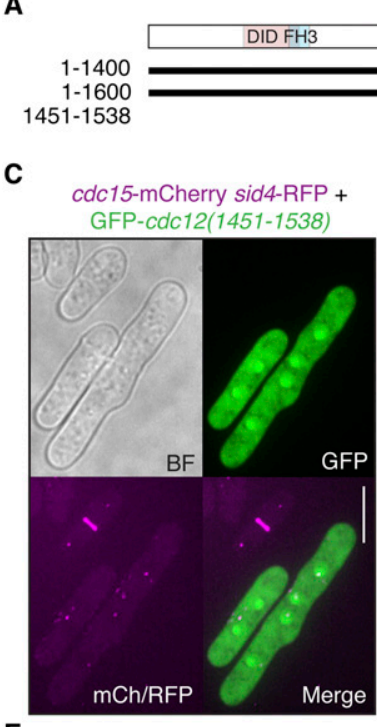

E

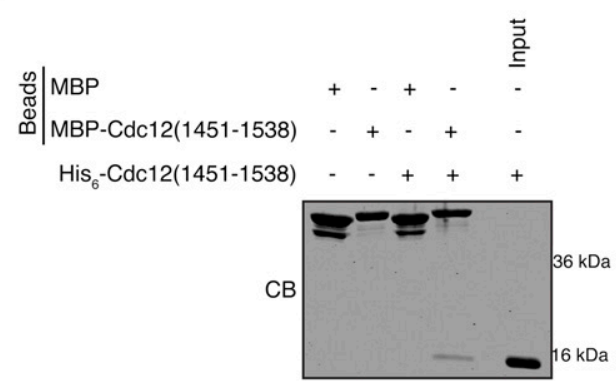

B

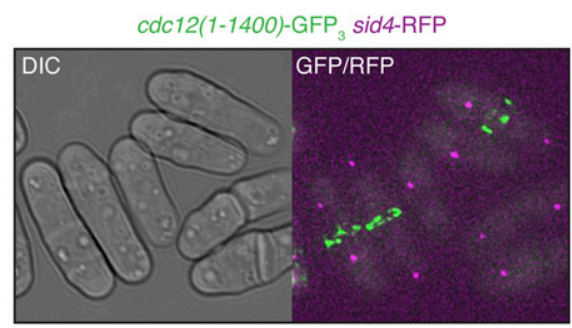

cdc12(1-1600)-GFP ${ }_{3}$ sid4-RFP

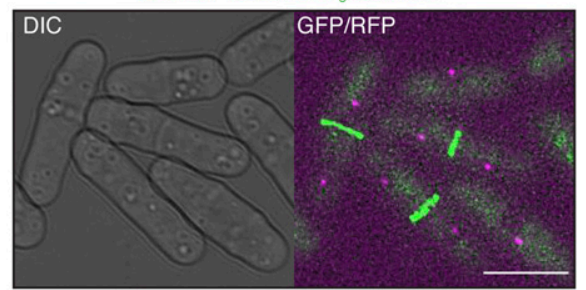

G

$\mathbf{F}$

H

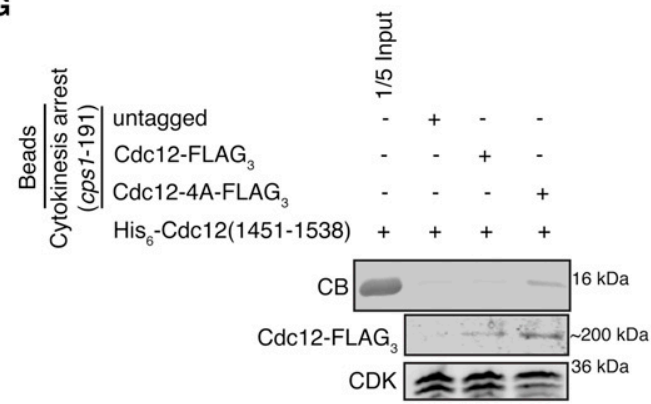

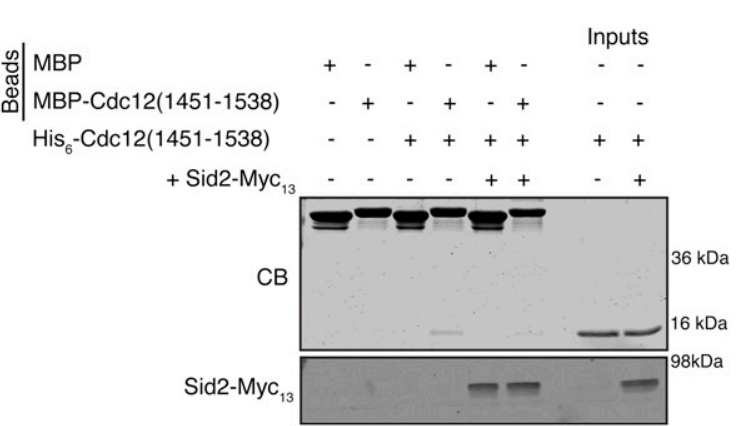

Figure 5. Multimerization of a Cdc12 C-terminal domain is inhibited by Sid2-mediated phosphorylation. $(A)$ Schematic of Cdc12, with relevant fragments illustrated, and Sid2-phosphorylated residues marked by red ticks. $(B)$ Live-cell differential interference contrast (DIC) and merged GFP/RFP images of $c d c 12(1-1400)-\mathrm{GFP}_{3}$ sid4-RFP and $c d c 12(1-1600)-\mathrm{GFP}_{3}$ sid4-RFP cells. (C) Live-cell bright-field, GFP, mCherry/RFP, and merged fluorescence images of cdc15-mCherry sid4-RFP cells, some of which overexpress GFP$c d c 12(1451-1538)$ from the pSGP572a plasmid. (D) Recombinant His 6 -Cdc12(1451-1538) was resolved under native or denaturing conditions, and protein gels were Coomassie blue-stained (CB). $(E)$ In vitro binding of bead-bound recombinant MBP or MBPCdc12(1451-1538) with recombinant His $_{6}$-Cdc12(1451-1538). Samples were washed, resolved by SDS-PAGE, and Coomassie bluestained. The His ${ }_{6}$-Cdc12(1451-1538) input is given as a control. $(F)$ Fixed-cell bright-field, GFP, and DAPI images of $c d c 12-$ GFP $_{3}$ cells defective in cytokinesis due to overexpression of $c d c 12(1451-1538)$ from the pREP1 plasmid. $(G)$ In vitro binding of recombinant His $6^{-}$ Cdc12(1451-1538) with bead-bound Cdc12-Flag or Cdc12-4A-Flag $_{3}$ immunoprecipitated from a cytokinesis arrest. Samples were washed and resolved by SDS-PAGE, and gel halves were either immunoblotted with an anti-Flag antibody or Coomassie blue-stained. One-fifth of the His $_{6}$-Cdc12(1451-1538) input is given as a control. Native cell lysates used in the anti-Flag immunoprecipitations were also resolved by SDS-PAGE and immunoblotted with anti-PSTAIR (CDK) as a control. $(H)$ In vitro binding of bead-bound recombinant MBP or MBP-Cdc12(1451-1538), which had been phosphorylated by Sid2-Myc ${ }_{13}$, with recombinant His ${ }_{6}$-Cdc12(1451-1538). Sid2$\mathrm{Myc}_{13}$ was initially immunoprecipitated from cdc16-116 sid2-Myc $\mathrm{c}_{13}$ cells and incubated with ATP and bead-bound recombinant proteins. An empty anti- $\mathrm{Myc}_{13}$ immunoprecipitate was used as a control in kinase reactions. Following binding to His ${ }_{6}$-Cdc12/1451-

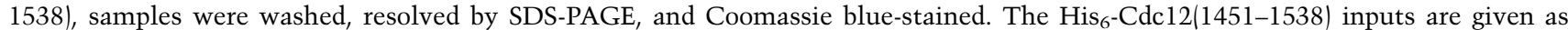
a control, as are immunoblots of $\mathrm{Sid} 2-\mathrm{Myc}_{13}$ used in the kinase reactions. Bars, $5 \mu \mathrm{m}$. 
Bohnert et al.

A

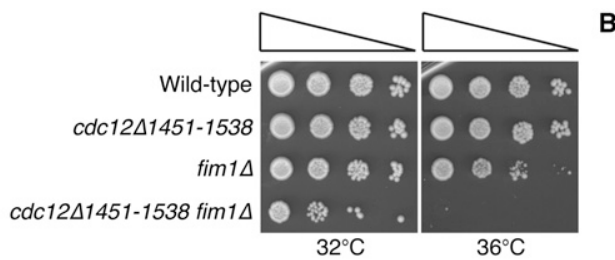

C

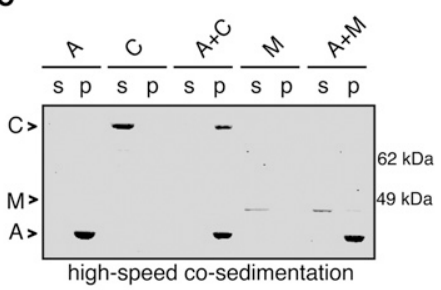

F
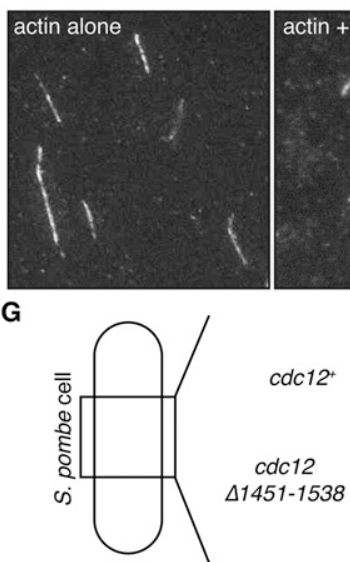

H
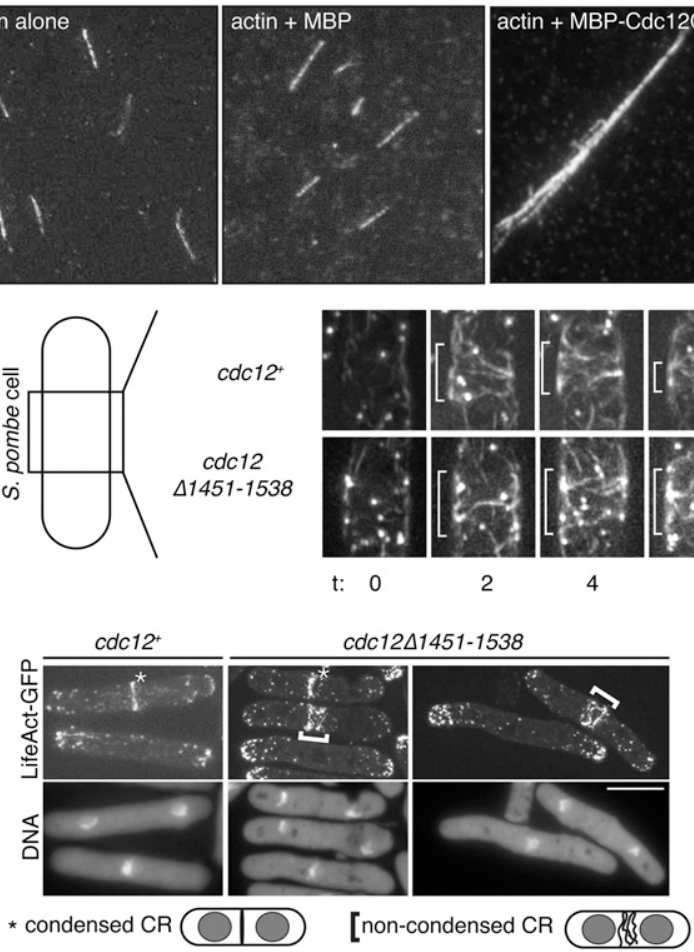

B

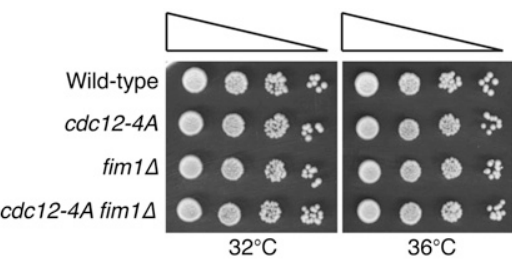

E

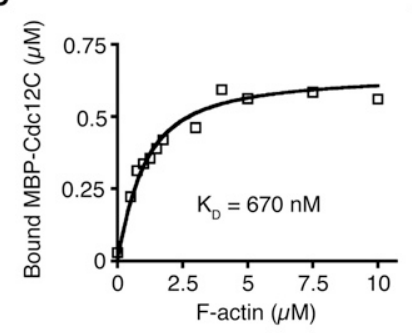

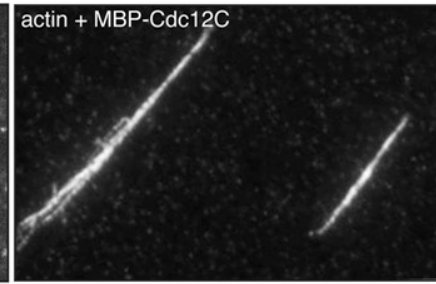
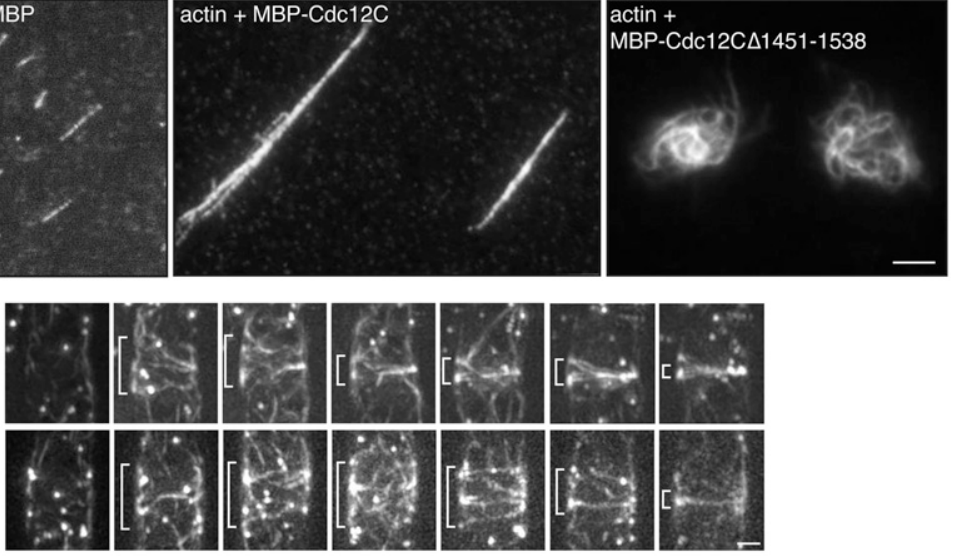

6

10.5

I

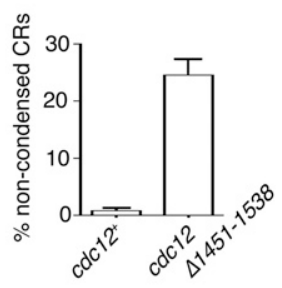

Figure 6. The Cdc12 C terminus bundles F-actin partly via its oligomerization domain. $(A, B)$ Serial 10-fold dilutions of the indicated strains at various temperatures. $(C)$ High-speed $(150,000 \mathrm{~g})$ sedimentation assay of MBP-Cdc12C (C) or MBP (M) with F-actin (A). Equal portions of supernatants $(\mathrm{s})$ and pellets $(\mathrm{p})$ were resolved by SDS-PAGE and then Coomassie blue-stained. $(D)$ Titration of MBP-Cdc12C binding to F-actin. High-speed $(150,000 g)$ sedimentations were performed with varying F-actin concentrations, and the amount of copelleted MBP$\mathrm{Cdc12C}$ was measured. The $\mathrm{K}_{\mathrm{D}}$ was determined by fitting a quadratic equation to these data. $(E)$ Low-speed $(10,000 \mathrm{~g})$ sedimentation assay of MBP-Cdc12C (C) or MBP (M) with F-actin (A). Equal portions of supernatants (s) and pellets (p) were resolved by SDS-PAGE and then Coomassie blue-stained. Asterisks indicate MBP-Cdc12C degradation products. $(F)$ Representative fluorescence images of rhodaminephalloidin-stained actin filaments in the absence or presence of MBP, MBP-Cdc12C, or MBP-Cdc12C $\Delta 1451-1538$. (G) Live-cell GFP movies of cdc25-22 LifeAct-GFP or cdc25-22 cdc12 $1451-1538$ LifeAct-GFP cells assembling a CR. Cells were grown at $25^{\circ} \mathrm{C}$. Frames show cell middles and start as actin accumulates medially. Images were acquired every $1.5 \mathrm{~min}$, and representative images are shown. Brackets span the breadth of medial actin. $(H)$ Fixed-cell GFP and DAPI images of $c d c 25-22$ LifeAct-GFP or cdc25-22 cdc1241451-1538 LifeAct-GFP cells grown at $25^{\circ} \mathrm{C}$. $(I)$ Quantification of condensed and noncondensed CRs in binucleate cdc25-22 LifeAct-GFP or binucleate cdc25-22 cdc12 1451-1538 LifeAct-GFP cells grown at $25^{\circ} \mathrm{C}$. Three trials, with $n>100$, were performed per genotype. Bars: $F, H, 5 \mu \mathrm{m} ; G, 1 \mu \mathrm{m}$.

contributes to F-actin bundling, an activity that Cdc12's $\mathrm{FH} 1$ and FH2 domains alone cannot perform (Scott et al. 2011).
We found that a C-terminal fragment ("Cdc12C," residues 1293-end) that contains the oligomerization domain but lacks the FH1FH2 region (Supplemental Fig. 6B) 
copelleted with F-actin in high-speed $(150,000 g)$ sedimentation assays (Fig. 6C). Titration of this binding event revealed a $\mathrm{K}_{\mathrm{D}}$ of $670 \mathrm{nM}$ (Fig. $6 \mathrm{D}$ ), which is similar to those described for other F-actin bundlers at the CR (Takaine et al. 2009). Notably, MBP-Cdc12C also copelleted with F-actin in low-speed $(10,000 \mathrm{~g})$ sedimentation assays (Fig. $6 \mathrm{E})$, indicating that it also cross-linked F-actin. Rhodamine-phalloidin staining further revealed the Cdc12 C terminus organized F-actin into long, linear bundles (Fig. 6F). Accordingly, the Cdc12 C terminus can both bind and bundle F-actin. Although a Cdc12C $\Delta 1451-1538$ mutant fragment that lacks the oligomerization domain (Supplemental Fig. 6B) bound F-actin with higher affinity than the intact $\mathrm{C}$ terminus (Supplemental Fig. 6C,D), this mutant did not bundle F-actin but instead formed disordered cross-links (Fig. 6F). Thus, the Cdc12 oligomerization domain supports the organization of F-actin into linear bundles in vitro, although this domain itself cannot efficiently bind F-actin (Supplemental Fig. 6E).

If Cdc12 multimerization facilitates F-actin bundling in vivo, we expected that a cdc1241451-1538 mutant would be defective in CR assembly. Indeed, imaging actin marker LifeAct-GFP in a $c d c 25-22$ mutant at permissive temperature, in which the longer cell length clarifies medial actin structures (Huang et al. 2012), gave the impression that deleting the multimerization domain compromised actin condensation into a discrete CR (Fig. 6G). Indeed, still and time-lapse imaging of Cdc12 $\Delta 1451-1538-\mathrm{GFP}_{3}$ hinted at defective CR condensation in this mutant (Supplemental Figs. 5F, 6F). To score this defect, we quantified condensed and noncondensed CRs in mitotic cdc25-22 cells at permissive temperature. We found that roughly a quarter of $c d c 12 \Delta 1451-1538$ binucleates possessed medial actin that had yet to condense into a ring (Fig. $6 \mathrm{H}, \mathrm{I})$. In contrast, nearly all $c d c 12^{+}$binucleates showed a condensed CR (Fig. 6H,I). These data suggest that Cdc12 multimerization initially facilitates ordered F-actin bundling to promote early stages of CR formation and that Sid2-based reversal of multimerization subsequently limits this activity.

\section{Discussion}

Although the SIN is a well-documented cytokinesis regulator, essential CR targets of this network had not been described. Here, we establish cytokinetic formin Cdc12 as a direct Sid2 target that is key to SIN-driven cytokinesis. Phosphoregulation of Cdc12 during cytokinesis appears to function as an oligomeric switch, promoting Cdc12 multimer disassembly necessary for $\mathrm{CR}$ maintenance (Fig. 7A,B). When left unchecked during late cytokinesis, persistent Cdc12 multimerization results in abnormal formin clustering, which leads to CR disintegration and failure of cell cleavage (Fig. 7B).

The intrinsic ability of Cdc12 to multimerize and cluster explains the origin of Cdc12-containing spots that have been detected in interphase cells (Fig. 7A; Yonetani et al. 2008; Coffman et al. 2009), cells overexpressing Cdc12 (Chang et al. 1997; Chang 1999; Carnahan and Gould 2003), and mutants with impaired SIN function (Fig. 4B). Why spots form and how they relate to formin activity and CR formation have been topics of debate (Roberts-Galbraith and Gould 2008). Although a previous study implicated Cdc12's N-terminal FH3 domain in spot formation, this same study demonstrated more dramatic clustering upon
A

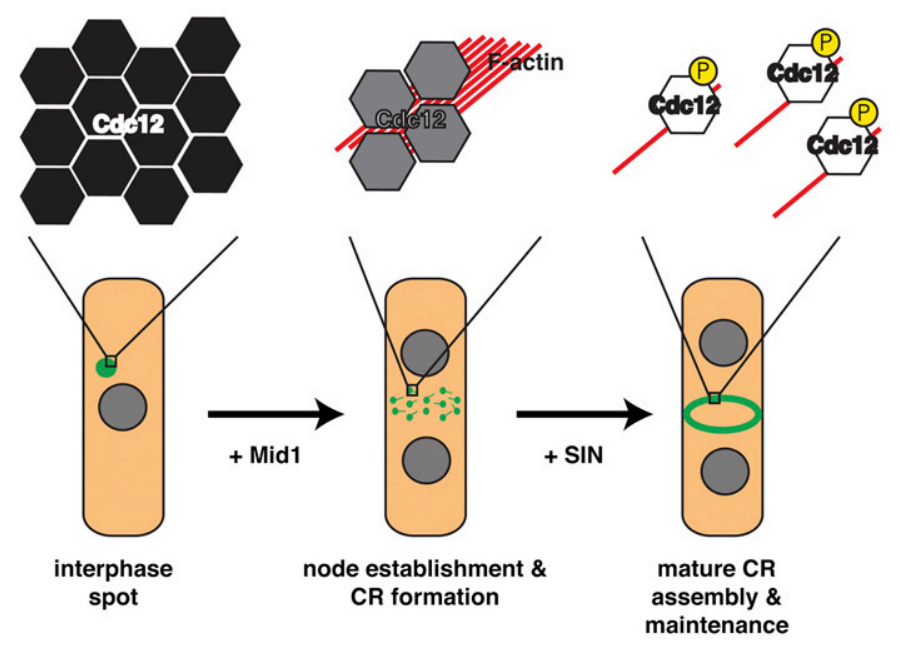

B

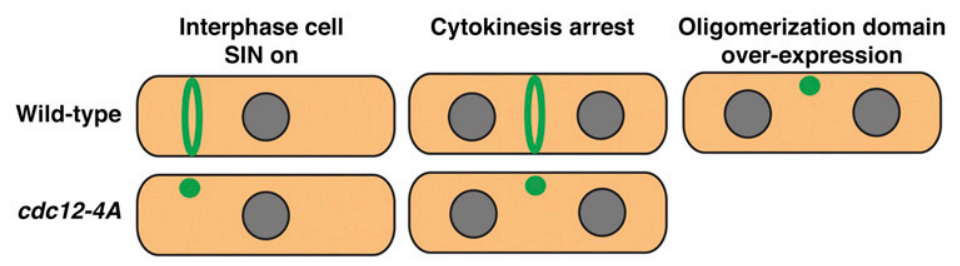

Figure 7. Model for Sid2-mediated Cdc12 phosphorylation in fission yeast cytokinesis. (A) During interphase, Cdc12 exists in a spot-like structure, which serves as a reservoir. At mitotic onset, anillin-like Mid1 assembles medial nodes to which Cdc12 and other CR factors are recruited. Nodes spatially restrict Cdc12 spot formation and aid in initial declustering. As CRs form from nodes, multimeric Cdc12 bundles F-actin, aiding in CR condensation. Upon full activation of the SIN, Sid2 phosphorylates Cdc12 to inhibit multimerization of Cdc12's C-terminal oligomerization domain. This oligomeric switch facilitates mature CR assembly and maintenance by blocking $\mathrm{Cdc} 12$ spot formation once Midl has exited the CR in late cytokinesis. (B) Typically, $c d c 12^{+}$cells maintain a CR during a cytokinesis arrest and undergo septation in interphase when the SIN is prematurely activated. In these contexts, CRs do not collapse because Cdc12 clustering is inhibited by the SIN. However, when the SIN kinase Sid2 cannot phosphorylate Cdc12, Cdc12 and other CR proteins cluster abnormally, similar to when Cdc12's oligomerization domain is overexpressed. Persistent multimerization leads to the formation of spot-like structures during a cytokinesis arrest or in SIN-activated interphase cells. Thus, Sid2-mediated Cdc12 phosphorylation constitutes a critical SIN signal, which reverses Cdc12 multimerization at the appropriate time to enable proper CR performance. 
overexpression of Cdc12's C terminus (Yonetani et al. 2008). Indeed, we found that C-terminal multimerization facilitates spot formation during interphase or when the self-association domain is hyperabundant (Fig. 7A,B). In both contexts, Cdc12 cannot induce cytokinesis, supporting the ideas that (1) spots serve as reservoirs that restrict formin function (Yonetani et al. 2008; Coffman et al. 2009), and (2) the Cdc12 C terminus possesses an inhibitory domain (Yonetani and Chang 2010). When interphase is prolonged and CR proteins prematurely localize to the division site, even more pronounced Cdc12 spots develop (Roberts-Galbraith et al. 2010). Thus, Cdc12 clusters can expand with time if relevant disassembly cues are not triggered.

How is the Cdc12 clustering/declustering cycle regulated? For the CR to form, Cdc12 spots must disassemble and remobilize into a ring-like structure. During early mitosis, Mid1/node-dependent pathways may initially antagonize Cdc12 clustering (Fig. 7A) because, in their absence, CRs assemble from spot-like asters (Huang et al. 2008). Two separate Mid1-dependent modules, based on either myosin and IQGAP Rng2 or Cdc15, recruit Cdc12 medially (Laporte et al. 2011), where Cdc12 likely binds multiple node proteins capable of serving as cortical anchors (Saha and Pollard 2012; Guzman-Vendrell et al. 2013). Presumably, these anchors spatially restrict Cdc12 clustering but permit some degree of Cdc12 multimerization that facilitates F-actin bundling (Fig. 7A). In support of Mid1/node-dependent pathways contributing declustering signals during CR formation, cdc12-4A cells undergo cytokinesis when the cell cycle is otherwise unperturbed. Despite Mid1-based compensation at the CR, Cdc12-4A still accumulates at SPBs during CR constriction, consistent with a multimer disassembly defect and other data suggesting an SPB-Cdc12-binding interface (Petersen et al. 1998).

Mid1 remains at the CR through its assembly (Sohrmann et al. 1996), although Mid1 exits during a cps1-191 arrest (Pardo and Nurse 2003). In Mid1's absence, other mechanisms must counteract formin clustering to prevent CR collapse. Our data show that Sid2-mediated phosphoinhibition of Cdc12 multimerization provides a mechanism to inhibit formin clustering during cytokinesis. Previous studies have demonstrated that phosphorylation can disrupt autoinhibitory formin interactions (Takeya et al. 2008; Wang et al. 2009). Our results provide a striking parallel, revealing that formin trans interactions, which mediate oligomerization, can also be phosphoregulated. While our model (Fig. 7A) proposes that tandem Mid1/ node- and SIN-dependent declustering signals ensure efficient CR assembly and maintenance, other mechanisms likely contribute to activation of formin nucleation and elongation activities because rudimentary filament-like structures still form in the absence of Mid1 and Sid2mediated Cdc12 phosphorylation (Fig. 3E).

Although it is well established that formin dimerization via FH2 domains allows efficient actin nucleation and barbed end elongation (Xu et al. 2004), it has been unclear whether formins can form higher-ordered oligomers and, if so, what function these oligomerization events would serve. In this study, we showed that C-terminal multimerization promotes Cdc12-mediated F-actin bundling. It seems reasonable that Cdc12 would possess an F-actin bundling domain because (1) node condensation and mature CR formation require F-actin bundling (Laporte et al. 2012), and (2) node-localized Cdc12 is ideally positioned for this task (Coffman et al. 2009). Our data indicate that Cdc12 may cooperate with myosin in pulling F-actin into a ring structure (Fig. 7A; Vavylonis et al. 2008), and this activity may be particularly useful for incorporating nonmedial F-actin cables into the CR (Huang et al. 2012). Because Cdc12 F-actin bundling activity correlates with its C-terminal oligomeric state, the Sid2-based phosphoregulatory switch must be precisely timed; whereas delayed reversal of multimerization during cytokinesis suspends formin declustering and precipitates CR collapse, premature loss of multimerization during early mitosis jeopardizes F-actin bundling and likewise hinders CR formation.

Formin-mediated F-actin bundling may shape the cytokinetic cytoskeleton in diverse species, as now both Cdc12 and the mammalian cytokinetic formin mDia2 (Watanabe et al. 2008) have been found to bundle F-actin (Harris et al. 2006; Esue et al. 2008; Machaidze et al. 2010). While F-actin bundling activities have been demonstrated for multiple eukaryotic formins, of these, only Cdc12 and mammalian FRL3 contain F-actin bundling domains distinct from their $\mathrm{FH} 1 \mathrm{FH} 2$ regions /Vaillant et al. 2008), and Cdc12 is the first known in which that activity is specifically regulated. Indeed, the separation of Cdc12's F-actin bundling and FH1FH2 domains likely allows for differential temporal control of nucleating and bundling activities and precludes competition between them. In the future, it should prove fruitful to determine how the Cdc12 C terminus, which we showed possesses F-actin bundling activity, impacts the well-characterized activities of the Cdc12 FH1 and/or FH2 domains.

\section{Materials and methods}

\section{Strains and general yeast methods}

S. pombe strains (Supplemental Table 1) were grown in yeast extract (YE) or Edinburgh minimal medium with relevant supplements. $c d c 12^{+}, c d c 12-4 A, c d c 12 \Delta 1451-1538, c d c 12$ truncations, $\mathrm{rpn}_{1} 1^{+}$, and $\mathrm{sid}^{+}$were tagged endogenously at the $3^{\prime}$ end with $\mathrm{HA}_{3}: \operatorname{kan}^{\mathrm{R}}, \mathrm{V}_{3}: \operatorname{kan}^{\mathrm{R}}, \mathrm{V}_{3}: \mathrm{hyg}^{\mathrm{R}}, \mathrm{Flag}_{3}: \operatorname{kan}^{\mathrm{R}}, \mathrm{Flag}_{3}: \mathrm{hyg}^{\mathrm{R}}$, $\mathrm{GFP}_{3}: \mathrm{kan}^{\mathrm{R}}{ }, \mathrm{GFP}_{3}:$ hyg $^{\mathrm{R}}$, RFP:nat ${ }^{\mathrm{R}}$, or myc $_{13}:$ hyg $^{\mathrm{R}}$ cassettes as previously described (Bahler et al. 1998). A lithium acetate method (Keeney and Boeke 1994) was used in S. pombe tagging transformations, and integration of tags was verified using whole-cell PCR and/or microscopy. Introduction of tagged loci into other strains was accomplished using standard S. pombe mating, sporulation, and tetrad dissection techniques.

Cell cycle arrests were achieved as follows: (1) cdc10-V50 cells were arrested in $\mathrm{G} 1$ by shifting cultures for $4 \mathrm{~h}$ to $36^{\circ} \mathrm{C}$. (2) $c d c 25$ 22 cells were arrested in G2 by shifting cultures for $3 \mathrm{~h}$ to $36^{\circ} \mathrm{C}$. (3) nda3-KM311 cells were arrested in prometaphase by shifting cultures for $6.5 \mathrm{~h}$ to $18^{\circ} \mathrm{C}$. (4) cps1-191 cells were arrested in cytokinesis by shifting cultures for $3 \mathrm{~h}$ to $36^{\circ} \mathrm{C}$. (5) Cells were arrested in $\mathrm{S}$ phase by growth in $12 \mathrm{mM}$ hydroxyurea (Sigma) for $3.5 \mathrm{~h}$ at $32^{\circ} \mathrm{C}$. For release from the $c d c 25-22 \mathrm{G} 2$ arrest, cultures 
were cooled immediately to $25^{\circ} \mathrm{C}$ on ice and then grown at $25^{\circ} \mathrm{C}$. For release from the hydroxyurea-induced S-phase arrest, yeast was filtered, washed in YE, and then grown at $32^{\circ} \mathrm{C}$.

SIN hyperactivation in $c d c 16-116$ strains was induced by shifting cultures for $3-4 \mathrm{~h}$ to $36^{\circ} \mathrm{C}$. When necessary, cells were first synchronized in interphase by centrifugal elutriation using an Avanti J-26 XPI centrifuge (Beckman Coulter).

To create the endogenous $c d c 12-4 A$ and $c d c 12 \Delta 1451-1538$ alleles, a pSK vector was constructed that contained the following in order: $5^{\prime} c d c 12$ flank, full-length $c d c 12^{+}, \operatorname{kan}^{\mathrm{R}}$ cassette, and 3' $c d c 12$ flank. Phosphorylation site mutations were created using a QuikChange multisite site-directed mutagenesis kit (Agilent Technologies) and confirmed by sequencing. For the internal deletion, Notl restriction sites were inserted before and after residues 1451 and 1538, respectively. After removal of residues 1451-1538 and religation, the Not 1 site was eliminated via mutagenesis, and the construct was resequenced. $c d c 12-4 \mathrm{~A}$ and $c d c 12 \Delta 1451-1538$ constructs were then cut from the vectors and transformed into wild-type $S$. pombe cells using a lithium acetate method. Kan-resistant cells were selected and sequenced to identify transformants containing appropriate mutations.

For Lat A treatment, either DMSO or DMSO containing Lat A was added to log-phase cultures. The final Lat A concentration was $0.2 \mu \mathrm{M}$. Cultures were kept for $8 \mathrm{~h}$ at $32^{\circ} \mathrm{C}$ before fixation and staining.

For spot assays, cells were grown to $\log$ phase at $25^{\circ} \mathrm{C}, 10$ million cells were resuspended in $1 \mathrm{~mL}$ of water, and $1-\mathrm{mL}$ serial dilutions were made. Each dilution $(2.5 \mu \mathrm{L})$ was plated on YE. Plates were incubated at various temperatures.

Overexpression of full-length $c d c 12^{+}$or $c d c 12$ fragments was controlled by the thiamine-repressible $n m t$ promoters of $\mathrm{pREP} 1$ or pSGP527a. Expression was kept off by addition of $5 \mu \mathrm{g} / \mathrm{mL}$ thiamine to the medium, and expression was induced by washing and/or culturing in medium lacking thiamine.

Truncations of $c d c 12$ were generated by PCR-mediated insertions of $\mathrm{V}_{3}$ or $\mathrm{GFP}_{3}$ after relevant amino acids

\section{Protein methods}

Cell pellets were snap-frozen in dry ice-ethanol baths. Lysates were prepared using a Fastprep cell homogenizer (MP Biomedicals). Immunoprecipitations were performed as previously described (Gould et al. 1991) in either NP40 buffer for native lysates or NP40 buffer containing SDS for denatured lysates. Protein samples were resolved by SDS-PAGE and transferred to PVDF membrane (Immobilon P, EMD Millipore). Anti-HA (12CA5), anti-Myc (9E10), anti-V5 (Invitrogen), anti-Flag (M2, Sigma), or anti-Cdc2 (Sigma) were used in immunoprecipitations and/or as primary antibodies in immunoblotting. Secondary antibodies were conjugated to IRDye680LT or IRDye800 (LI-COR Biosciences). Blotted proteins were detected via an Odyssey machine (LI-COR Biosciences). For gel shifts, denatured lysates were treated with $\lambda$-phosphatase (New England Biolabs) in $25 \mathrm{mM}$ HEPES-NaOH $/ \mathrm{pH}$ 7.4), $150 \mathrm{mM} \mathrm{NaCl}$, and $1 \mathrm{mM} \mathrm{MnCl}_{2}$ and incubated for $30 \mathrm{~min}$ at $30^{\circ} \mathrm{C}$ with shaking. Where indicated, samples were resolved by SDS-PAGE in the presence of $5 \mu \mathrm{M}$ PhosTag acrylamide per the manufacturer's protocol (Wako Chemical).

Recombinant proteins were produced in competent BL21 cells and purified on amylose beads (New England Biolabs) or His-Bind resin (EMD Millipore) according to the manufacturers' protocols. When necessary, recombinant proteins were concentrated using Amicon Ultra centrifugal filter units (EMD Millipore). PD-10 columns (GE Healthcare) were used for buffer exchange of eluted recombinant proteins included in F-actin assays; the final buffer for these proteins was $50 \mathrm{mM}$ HEPES (pH 7.5). Native gel analysis of recombinant proteins was performed in the absence of SDS.

For in vitro binding assays, recombinant proteins were incubated together or with cellular immunoprecipitates for $1 \mathrm{~h}$ at $4^{\circ} \mathrm{C}$. Following washing, samples were resolved by SDS-PAGE for Coomassie blue staining or Western blot analysis.

In vitro kinase assays were performed using the Sid2-Mob1 kinase complex immunoprecipitated from SIN-activated sid2$\mathrm{Myc}_{13}$ cdc16-116 or sid2-Myc $\mathrm{y}_{13}$ cdc16-116 cdc12-4A cells. Myelin basic protein (Sigma) was used as a control substrate for Sid2-Myc $\mathrm{C}_{13}$ (Feoktistova et al. 2012). [ $\left.\gamma^{32} \mathrm{P}\right]$ ATP kinase assays, phosphoamino acid analysis, and tryptic peptide mapping were performed as described in Sparks et al. (1999) and Feoktistova et al. (2012) and references therein. In vitro phosphorylation of recombinant proteins used in in vitro binding assays was performed via identical kinase assays, except that radioactive $\left[\gamma^{32} \mathrm{P}\right] \mathrm{ATP}$ was eliminated, and the final concentration of unlabeled ATP in reactions was increased to $2 \mathrm{mM}$.

\section{F-actin binding and bundling assays}

To analyze F-actin binding and bundling, rabbit skeletal muscle actin (Cytoskeleton, Inc.) was resuspended in general actin buffer (5 mM Tris $\mathrm{HCl}$ at $\mathrm{pH} 8,0.2 \mathrm{mM} \mathrm{CaCl}_{2}, 0.2 \mathrm{mM}$ ATP, $0.5 \mathrm{mM}$ DTT) to a concentration of $24 \mu \mathrm{M}$. This was kept for $1 \mathrm{~h}$ on ice. We then added $10 \times$ polymerization buffer $(500 \mathrm{mM} \mathrm{KCl}, 20 \mathrm{mM}$ $\mathrm{MgCl}_{2}, 10 \mathrm{mM}$ ATP) to a final concentration of $1 \times$ and nutated tubes for $1 \mathrm{~h}$ at room temperature. F-actin $(3 \mu \mathrm{m})$ was subsequently incubated with recombinant proteins for $30 \mathrm{~min}$ at room temperature, and samples were either centrifuged or diluted 1:100 in $70 \mathrm{nM}$ rhodamine-phalloidin (Cytoskeleton, Inc.) for imaging. High-speed centrifugation at $150,000 \mathrm{~g}$ and low-speed centrifugation at $10,000 \mathrm{~g}$ were performed for $30 \mathrm{~min}$ at room temperature using a TLA-100 rotor (Beckman Coulter) or a Centrifuge 5424 (Eppendorf), respectively. Following centrifugation, pellets and supernatants were separated, and equal portions of pellets and supernatants were resolved by SDS-PAGE for Coomassie blue staining. The affinity $\left(\mathrm{K}_{\mathrm{D}}\right)$ of $\mathrm{Cdc} 12$ fragments for F-actin was calculated by fitting a quadratic equation to high-speed binding data.

\section{Microscopy}

Fixed-and live-cell images of $S$. pombe cells were acquired using one of the following: (1) a spinning disc confocal microscope (Ultraview LCI, PerkinElmer) equipped with a $100 \times$ NA 1.40 PlanApo oil immersion objective, a 488-nm argon ion laser (GFP), a 594-nm helium neon laser (RFP and mCherry), a charge-coupled device camera (Orca-ER, Hamamatsu Phototonics), and Metamorph 7.1 software (MDS Analytical Technologies and Molecular Devices) or (2) a personal DeltaVision microscope system (Applied Precision) that includes an Olympus IX71 microscope, 60× NA 1.42 PlanApo and 100× NA 1.40 UPlanSApo objectives, fixed- and live-cell filter wheels, a Photometrics CoolSnap HQ2 camera, and softWoRx imaging software.

All cells were grown to and/or arrested in log phase before fixation or live-cell imaging. For nuclei and cell wall imaging, cells were fixed in $70 \%$ ethanol for $30 \mathrm{~min}$ before DAPI and/or methyl blue staining. For phalloidin staining, cells were fixed in formaldehyde (Polysciences, Inc.) for $5 \mathrm{~min}$, and fixation was stopped by addition of PBS. Cells were washed three times in PBS and incubated with $0.1 \%$ NP40 for $1 \mathrm{~min}$ to permeabilize cells. Cells were pelleted and washed three more times in PBS. Next, Alexa-Fluor 488 phalloidin (Molecular Probes) was added. Samples were placed on a nutator for $1 \mathrm{~h}$ and then stained with DAPI if necessary. 
sid4-SA1 cells were shifted for $30 \mathrm{~min}$ to $36^{\circ} \mathrm{C}$ before imaging sid2-as4 analog-sensitive strains were grown in the presence or absence of $20 \mu \mathrm{M}$ 3-MB-PP1 (Toronto Research Chemicals) for 15 min before imaging.

Time-lapse imaging was performed using an ONIX microfluidics perfusion system (CellASIC). Cells were loaded into Y04C plates for $5 \mathrm{sec}$ at $8 \mathrm{psi}$, and YE liquid medium flowed into the chamber at 5 psi throughout imaging. Time-lapse imaging of cdc16-116 and cps1-191 cells was initiated $30 \mathrm{~min}$ after cells were shifted to the restrictive temperature, which was maintained by a heated chamber. All imaging of LifeAct-GFP in $c d c 25-22$ and $c d c 25-22 c d c 12 \Delta 1451-1538$ cells was performed at the permissive temperature $\left(25^{\circ} \mathrm{C}\right)$.

Rhodamine-phalloidin-stained actin filaments and/or bundles were imaged using the DeltaVision system.

\section{Acknowledgments}

We thank Anna Feoktistova and Alyssa Johnson for technical assistance, and Rachel Roberts-Galbraith, Janel McLean, Jessi Mazerik, Matt Tyska, and members of the Gould and Kovar laboratories for helpful advice. We also thank Mohan Balasubramanian for contributing LifeAct constructs prior to publication, and Iain Hagan for strains. We are grateful for the following support: $\mathrm{NIH}$ grants T32-CA119925 (to K.A.B.), GM079265 (to D.R.K.), and GM101035 (to K.L.G.).

\section{References}

Ayscough KR, Stryker J, Pokala N, Sanders M, Crews P, Drubin DG. 1997. High rates of actin filament turnover in budding yeast and roles for actin in establishment and maintenance of cell polarity revealed using the actin inhibitor latrunculin-A. J Cell Biol 137: 399-416.

Bahler J, Wu JQ, Longtine MS, Shah NG, McKenzie A 3rd, Steever AB, Wach A, Philippsen P, Pringle JR. 1998. Heterologous modules for efficient and versatile PCR-based gene targeting in Schizosaccharomyces pombe. Yeast 14: 943 951.

Bothos I, Tuttle RL, Ottey M, Luca FC, Halazonetis TD. 2005. Human LATS1 is a mitotic exit network kinase. Cancer Res 65: 6568-6575.

Boucher L, Ouzounis CA, Enright AJ, Blencowe BJ. 2001. A genome-wide survey of RS domain proteins. RNA 7: 1693-1701.

Carnahan RH, Gould KL. 2003. The $\mathrm{PCH}$ family protein Cdc15p, recruits two F-actin nucleation pathways to coordinate cytokinetic actin ring formation in Schizosaccharomyces pombe. J Cell Biol 162: 851-862.

Chang F. 1999. Movement of a cytokinesis factor cdc12p to the site of cell division. Curr Biol 9: 849-852.

Chang F, Woollard A, Nurse P. 1996. Isolation and characterization of fission yeast mutants defective in the assembly and placement of the contractile actin ring. J Cell Sci 109: 131142.

Chang F, Drubin D, Nurse P. 1997. cdc12p, a protein required for cytokinesis in fission yeast, is a component of the cell division ring and interacts with profilin. J Cell Biol 137: 169182

Chen CT, Feoktistova A, Chen JS, Shim YS, Clifford DM, Gould $\mathrm{KL}$, McCollum D. 2008. The SIN kinase Sid2 regulates cytoplasmic retention of the $S$. pombe Cdc14-like phosphatase Clp1. Curr Biol 18: 1594-1599.

Clifford DM, Wolfe BA, Roberts-Galbraith RH, McDonald WH Yates JR 3rd, Gould KL. 2008. The Clp1/Cdc14 phosphatase contributes to the robustness of cytokinesis by association with anillin-related Mid1. J Cell Biol 181: 79-88.
Coffman VC, Nile AH, Lee IJ, Liu H, Wu JQ. 2009. Roles of formin nodes and myosin motor activity in Midlp-dependent contractile-ring assembly during fission yeast cytokinesis. Mol Biol Cell 20: 5195-5210.

Esue O, Harris ES, Higgs HN, Wirtz D. 2008. The filamentous actin cross-linking/bundling activity of mammalian formins. J Mol Biol 384: 324-334.

Feoktistova A, Morrell-Falvey J, Chen JS, Singh NS, Balasubramanian MK, Gould KL. 2012. The fission yeast septation initiation network (SIN) kinase, Sid2, is required for SIN asymmetry and regulates the SIN scaffold, Cdc11. Mol Biol Cell 23: $1636-1645$.

Fujiwara T, Bandi M, Nitta M, Ivanova EV, Bronson RT, Pellman D. 2005. Cytokinesis failure generating tetraploids promotes tumorigenesis in p53-null cells. Nature 437: 1043-1047.

Gould KL, Moreno S, Owen DJ, Sazer S, Nurse P. 1991. Phosphorylation at Thr167 is required for Schizosaccharomyces pombe p34cdc2 function. EMBO J 10: 3297-3309.

Grallert A, Connolly Y, Smith DL, Simanis V, Hagan IM. 2012. The $S$. pombe cytokinesis NDR kinase Sid2 activates Fin1 NIMA kinase to control mitotic commitment through Pom1/ Weel. Nat Cell Biol 14: 738-745.

Guertin DA, Trautmann S, McCollum D. 2002. Cytokinesis in eukaryotes. Microbiol Mol Biol Rev 66: 155-178.

Gupta S, Mana-Capelli S, McLean JR, Chen CT, Ray S, Gould KL, McCollum D. 2013. Identification of SIN pathway targets reveals mechanisms of crosstalk between NDR kinase pathways. Curr Biol 23: 333-338.

Guzman-Vendrell M, Baldissard S, Almonacid M, Mayeux A, Paoletti A, Moseley JB. 2013. Blt1 and Mid1 provide overlapping membrane anchors to position the division plane in fission yeast. Mol Cell Biol 33: 418-428.

Hachet O, Simanis V. 2008. Midlp/anillin and the septation initiation network orchestrate contractile ring assembly for cytokinesis. Genes Dev 22: 3205-3216.

Harris ES, Rouiller I, Hanein D, Higgs HN. 2006. Mechanistic differences in actin bundling activity of two mammalian formins, FRL1 and mDia2. I Biol Chem 281: 14383-14392.

Hergovich A, Hemmings BA. 2012. Hippo signalling in the G2/M cell cycle phase: Lessons learned from the yeast MEN and SIN pathways. Semin Cell Dev Biol 23: 794-802.

Huang Y, Yan H, Balasubramanian MK. 2008. Assembly of normal actomyosin rings in the absence of Midlp and cortical nodes in fission yeast. J Cell Biol 183: 979-988.

Huang J, Huang Y, Yu H, Subramanian D, Padmanabhan A, Thadani R, Tao Y, Tang X, Wedlich-Soldner R, Balasubramanian MK. 2012. Nonmedially assembled F-actin cables incorporate into the actomyosin ring in fission yeast. J Cell Biol 199: 831847.

Johnson AE, McCollum D, Gould KL. 2012. Polar opposites: Fine-tuning cytokinesis through SIN asymmetry. Cytoskeleton (Hoboken) 69: 686-699.

Keeney JB, Boeke JD. 1994. Efficient targeted integration at leu132 and ura4-294 in Schizosaccharomyces pombe. Genetics 136: 849-856.

Kouranti I, McLean JR, Feoktistova A, Liang P, Johnson AE, Roberts-Galbraith RH, Gould KL. 2010. A global census of fission yeast deubiquitinating enzyme localization and interaction networks reveals distinct compartmentalization profiles and overlapping functions in endocytosis and polarity. PLoS Biol 8: e1000471.

Kovar DR, Pollard TD. 2004. Insertional assembly of actin filament barbed ends in association with formins produces piconewton forces. Proc Natl Acad Sci 101: 14725-14730.

Kovar DR, Kuhn JR, Tichy AL, Pollard TD. 2003. The fission yeast cytokinesis formin $\mathrm{Cdc} 12 \mathrm{p}$ is a barbed end actin 
filament capping protein gated by profilin. I Cell Biol 161: 875-887.

Laporte D, Coffman VC, Lee IJ, Wu JQ. 2011. Assembly and architecture of precursor nodes during fission yeast cytokinesis. J Cell Biol 192: 1005-1021.

Laporte D, Ojkic N, Vavylonis D, Wu JQ. 2012. $\alpha$-Actinin and fimbrin cooperate with myosin II to organize actomyosin bundles during contractile-ring assembly. Mol Biol Cell 23: 3094-3110.

Le Goff X, Woollard A, Simanis V. 1999. Analysis of the cps1 gene provides evidence for a septation checkpoint in Schizosaccharomyces pombe. Mol Gen Genet 262: 163-172.

Liu J, Wang H, McCollum D, Balasubramanian MK. 1999. Drclp/Cpslp, a 1,3- $\beta$-glucan synthase subunit, is essential for division septum assembly in Schizosaccharomyces pombe. Genetics 153: 1193-1203.

Liu J, Wang H, Balasubramanian MK. 2000. A checkpoint that monitors cytokinesis in Schizosaccharomyces pombe. J Cell Sci 113: 1223-1230.

Machaidze G, Sokoll A, Shimada A, Lustig A, Mazur A, Wittinghofer A, Aebi U, Mannherz HG. 2010. Actin filament bundling and different nucleating effects of mouse Diaphanous-related formin $\mathrm{FH} 2$ domains on actin/ADF and actin/ cofilin complexes. J Mol Biol 403: 529-545.

Mah AS, Elia AE, Devgan G, Ptacek J, Schutkowski M, Snyder M, Yaffe MB, Deshaies RJ. 2005. Substrate specificity analysis of protein kinase complex Dbf2-Mob1 by peptide library and proteome array screening. BMC Biochem 6: 22 .

Mana-Capelli S, McLean JR, Chen CT, Gould KL, McCollum D. 2012. The kinesin-14 Klp2 is negatively regulated by the SIN for proper spindle elongation and telophase nuclear positioning. Mol Biol Cell 23: 4592-4600.

Minet M, Nurse P, Thuriaux P, Mitchison JM. 1979. Uncontrolled septation in a cell division cycle mutant of the fission yeast Schizosaccharomyces pombe. J Bacteriol 137: 440-446.

Mishra M, Karagiannis J, Trautmann S, Wang H, McCollum D, Balasubramanian MK. 2004. The Clp1p/Flp1p phosphatase ensures completion of cytokinesis in response to minor perturbation of the cell division machinery in Schizosaccharomyces pombe. J Cell Sci 117: 3897-3910.

Nikolakaki E, Drosou V, Sanidas I, Peidis P, Papamarcaki T, Iakoucheva LM, Giannakouros T. 2008. RNA association or phosphorylation of the RS domain prevents aggregation of RS domain-containing proteins. Biochim Biophys Acta 1780: 214-225.

Pardo M, Nurse P. 2003. Equatorial retention of the contractile actin ring by microtubules during cytokinesis. Science 300: 1569-1574.

Peng TY, Lee KR, Tarn WY. 2008. Phosphorylation of the arginine/serine dipeptide-rich motif of the severe acute respiratory syndrome coronavirus nucleocapsid protein modulates its multimerization, translation inhibitory activity and cellular localization. FEBS J 275: 4152-4163.

Petersen J, Nielsen O, Egel R, Hagan IM. 1998. FH3, a domain found in formins, targets the fission yeast formin Fus1 to the projection tip during conjugation. J Cell Biol 141: 1217-1228.

Pollard TD, Wu JQ. 2010. Understanding cytokinesis: Lessons from fission yeast. Nat Rev Mol Cell Biol 11: 149-155.

Roberts-Galbraith RH, Gould KL. 2008. Stepping into the ring: The SIN takes on contractile ring assembly. Genes Dev 22: 3082-3088.

Roberts-Galbraith RH, Ohi MD, Ballif BA, Chen JS, McLeod I, McDonald WH, Gygi SP, Yates JR 3rd, Gould KL. 2010. Dephosphorylation of F-BAR protein Cdc15 modulates its conformation and stimulates its scaffolding activity at the cell division site. Mol Cell 39: 86-99.
Saha S, Pollard TD. 2012. Anillin-related protein Midlp coordinates the assembly of the cytokinetic contractile ring in fission yeast. Mol Biol Cell 23: 3982-3992.

Scott BJ, Neidt EM, Kovar DR. 2011. The functionally distinct fission yeast formins have specific actin-assembly properties. Mol Biol Cell 22: 3826-3839.

Skau CT, Courson DS, Bestul AJ, Winkelman JD, Rock RS, Sirotkin V, Kovar DR. 2011. Actin filament bundling by fimbrin is important for endocytosis, cytokinesis, and polarization in fission yeast. J Biol Chem 286: 26964-26977.

Sohrmann M, Fankhauser C, Brodbeck C, Simanis V. 1996. The $d m f 1 / m i d 1$ gene is essential for correct positioning of the division septum in fission yeast. Genes Dev 10: 2707-2719.

Sparks CA, Morphew M, McCollum D. 1999. Sid2p, a spindle pole body kinase that regulates the onset of cytokinesis. J Cell Biol 146: 777-790.

Takaine M, Numata O, Nakano K. 2009. Fission yeast IQGAP arranges actin filaments into the cytokinetic contractile ring. EMBO J 28: 3117-3131.

Takeya R, Taniguchi K, Narumiya S, Sumimoto H. 2008. The mammalian formin FHOD1 is activated through phosphorylation by ROCK and mediates thrombin-induced stress fibre formation in endothelial cells. EMBO J 27: 618-628.

Vaillant DC, Copeland SJ, Davis C, Thurston SF, Abdennur N, Copeland JW. 2008. Interaction of the $\mathrm{N}$ - and C-terminal autoregulatory domains of FRL2 does not inhibit FRL2 activity. I Biol Chem 283: 33750-33762.

Vavylonis D, Wu JQ, Hao S, O'Shaughnessy B, Pollard TD. 2008. Assembly mechanism of the contractile ring for cytokinesis by fission yeast. Science 319: 97-100.

Wang J, Neo SP, Cai M. 2009. Regulation of the yeast formin Bnilp by the actin-regulating kinase Prk1p. Traffic 10: 528 535.

Watanabe S, Ando Y, Yasuda S, Hosoya H, Watanabe N, Ishizaki T, Narumiya S. 2008. mDia2 induces the actin scaffold for the contractile ring and stabilizes its position during cytokinesis in NIH 3T3 cells. Mol Biol Cell 19: 2328-2338.

Xu Y, Moseley JB, Sagot I, Poy F, Pellman D, Goode BL, Eck MJ. 2004. Crystal structures of a formin homology-2 domain reveal a tethered dimer architecture. Cell 116: 711-723.

Yonetani A, Chang F. 2010. Regulation of cytokinesis by the formin cdc12p. Curr Biol 20: 561-566.

Yonetani A, Lustig RJ, Moseley JB, Takeda T, Goode BL, Chang F. 2008. Regulation and targeting of the fission yeast formin cdc12p in cytokinesis. Mol Biol Cell 19: 2208-2219. 


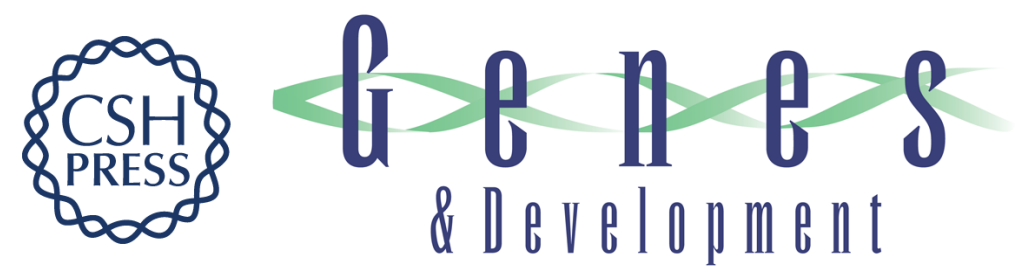

\section{SIN-dependent phosphoinhibition of formin multimerization controls fission yeast cytokinesis}

K. Adam Bohnert, Agnieszka P. Grzegorzewska, Alaina H. Willet, et al.

Genes Dev. 2013, 27:

Access the most recent version at doi:10.1101/gad.224154.113

\section{Supplemental http://genesdev.cshlp.org/content/suppl/2013/10/10/27.19.2164.DC1 Material}

References This article cites 60 articles, 39 of which can be accessed free at: http://genesdev.cshlp.org/content/27/19/2164.full.html\#ref-list-1

Creative This article is distributed exclusively by Cold Spring Harbor Laboratory Press for the first Commons six months after the full-issue publication date (see

License http://genesdev.cshlp.org/site/misc/terms.xhtml). After six months, it is available under a Creative Commons License (Attribution-NonCommercial 3.0 Unported), as described at http://creativecommons.org/licenses/by-nc/3.0/.

Email Alerting Receive free email alerts when new articles cite this article - sign up in the box at the top Service right corner of the article or click here.

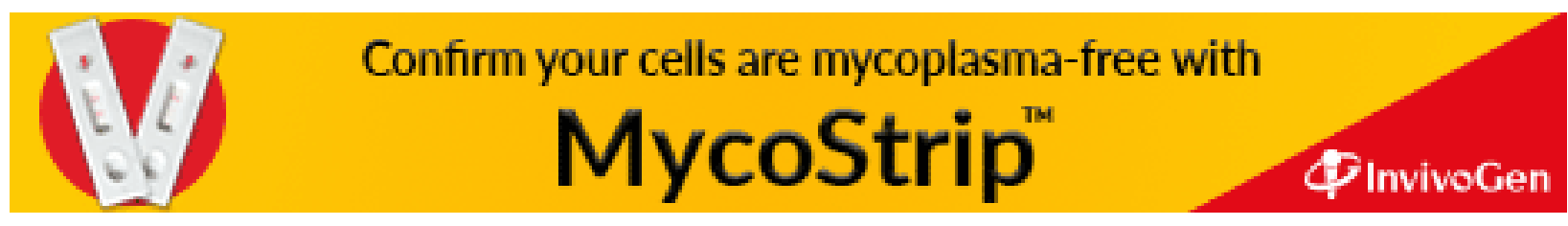

